Evidence in Practice 


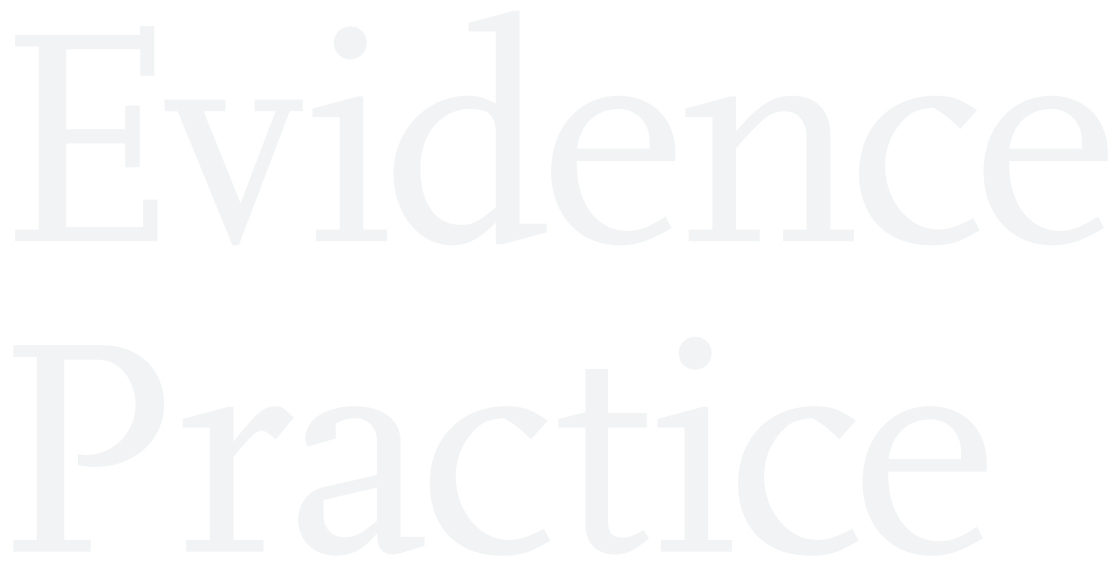




\section{Evidence in Practice}

On Knowledge Use and Learning in Social Work

\section{Gunilla Avby}

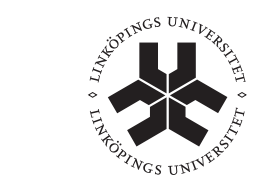

\section{Linköping University}

Linköping Studies in Arts and Science No 641

Linköping Studies in Behavioural Science No 192

Linköping University, Department of Behavioural Sciences and Learning 
Linköping Studies in Arts and Science No 641

Linköping Studies in Behavioural Science No 192

In the Faculty of Arts and Sciences at Linköping University, research and doctoral training is carried out within broad problem areas. Research is organized in interdisciplinary research environments, and doctoral studies done mainly in research institutes. Together they publish the Linköping Studies in Arts and Science series. This thesis comes from the Division of Education and Sociology at the Department of Behavioural Sciences and Learning.

Distributed by;

Department of Behavioural Sciences and Learning

Linköping University

SE- 58183 Linköping

Gunilla Avby

Evidence in Practice

On Knowledge Use and Learning in Social Work

Edition 1:1

ISSN: 0282-9800

ISSN: $1654-2029$

ISBN: 978-91-7519-088-4

(C) Gunilla Avby

Department of Behavioural Sciences and Learning 2015

Graphic design: Johan W Avby

Printed by: LIU-Tryck, Linköping 2015 
For my father Lars-Olov Larson 

It is necessary to combine knowledge born from study with sincere practice in our daily lives.

These two must go together.

Dalai Lama 



\section{Preface}

The Children Services Department decides to open investigations on two reports of child abuse. The social workers that are responsible for the cases have just ended a meeting with one of the parents.

BEA I wish there was more time to discuss alarming matters afterwards. To take some time and just reflect on the experience, but, then again, it probably just reflects the fact that I am still quite new on the job. I feel secure with the triangle (ввіс image) at hand. It's probably more for me than for the client.

AnNa It's about getting acquainted with and learning the method. To practice, test and consult the literature. I take it as it comes, others might have a very clear structure with fixed questions to manage the dialogue, but I don't. It doesn't help me to sit down and reflect after a meeting, I'd rather reflect on the run.

BEA But how do you know when you've got enough to decide upon? Working from a report is very vague. I could use more time to reflect, it would help me get things right. There's no reason I couldn't take the time and just add an half an hour after a meeting to write and reflect, but I don't. I think that I've just got into the habit of doing what I've always done.

Anna There is always so much to do. Although I believe that we have control of our own time, I want to help this troubled family now, along with the rest of the families I am responsible for, so I just pack my calendar full of additional meetings.

EXCERPT FROM STUdy IV

In the months that follow an extensive detective work takes place uncovering conflicting stories from the parties involved. The social workers are faced with a complex reality in which they are to decide whether or not the parents are capable of caring for and protecting the children, based on the evidence they are qualified to find. 



\section{Contents}

Preface

List of publications

1. Introduction

2. Background

Professional work in transition 17

Evidence-based practice gains ground 19

The import of evidence-based principles into Swedish social work

3. Theoretical framework

The concept of knowledge 26

Two different but complementary knowledge forms _ 27

The concept of knowledge use 30

Professional learning at work 32

Learning as transformations between tacit and explicit knowledge 32

Two modes of learning in work 34

Reflection and intuition in professional expertise $\quad 35$

4. Previous research 38

What counts as valuable knowledge for practice? 38

Use of research in practice 39

Knowledge for decision making in practice $\quad 40$

Learning in work 41

Evidence-based practice meets social work_ 42

5. Aim and research questions $\quad 45$ 
6. Methods 46

Research setting $\quad 46$

Child welfare services in Sweden $\quad 46$

A focus on investigation work 47

The local research setting 48

Methodological approaches _ 49

Conceptual case study $\quad 49$

Phenomenography $\quad 50$

Ethnography $\quad 50$

Research process 51

Quality of the research project 56

On research ethics 59

My role as a researcher 60

7. Summaries of studies 62

8. Discussion 67

Main research findings 67

Evidence-based practice - a legitimation of the status quo

or a driving force for development?

Learning as reproduction or development of professional knowledge? 71

An emergent model of evidence-based practice 73

Methodological considerations 74

Implications for practice and research 75

$\begin{array}{ll}\text { Acknowledgements } & 78\end{array}$

References $\quad 80$ 


\section{List of publications}

Article I. Nilsen, P., Nordström (Avby), G. and Ellström, P-E. (20II) Integrating research-based and practice-based knowledge through workplace reflection. Journal of Workplace Learning, 24(6), 403-415.

Article ir. Avby, G., Nilsen, P. and Abrandt Dahlgren, M. (2013) Ways of Understanding Evidence-Based Practice in Social Work: A Qualitative Study. British Journal of Social Work, 44(6), ז366-г383.

Article III. Avby, G., Nilsen, P. and Ellström, P-E. (20I5) Knowledge Use and Learning in Everyday Social Work Practice: A study in Child Investigation Work. Child E Family Social Work. Accepted: I4 February 20I5.

Article iv. Avby, G. (2015) Professional Practice as Processes of Muddling Through: A Study of Learning and Sense Making in Social Work. Vocations and Learning: Studies in Vocational and Professional Education 8(I), 95-II3. 



\section{Introduction}

Over the Last Decades, evidence-based practice approaches to making decisions have been portrayed as marking a new era of progress in different welfare sectors and as offering great promise for the development of a range of professional practices.

A key principle of evidence-based practice is that practice should be based on the most up-to-date and trustworthy scientific knowledge. The imperative to provide clients, patients and service users the best possible treatments and services has a strong political bearing, the notion of evidence-based having become something of a buzzword in the public debate (Kvernbekk 2orI). Although a broad range of helping professions assumes evidence-based criteria as the building blocks of practice, there is an on-going debate on what constitutes evidence-based practice and what it has to offer.

In the present thesis, social work is in focus, more specifically Swedish child welfare services. Up until the beginning of the I990s, work in child welfare was considered a high-status profession. Today, Swedish children's services departments tend to be staffed by young women, who have limited workplace support and many of whom resign within two to three years (Lindquist 20I2). The high personnel turnover and lack of resources are thought to curb possibilities to maintain and develop professional knowledge and practice, suggesting an organization under strong pressure (Socialstyrelsen 2015).

A long-standing debate surrounding evidence-based practice within social work is the conflicting viewpoints on what is considered to be valid knowledge for practice (Pawson et al. 2003; Trevithick 2008). The culture in social work tends to recognize knowledge generated in practice (Sheppard et al. 2000). That means individual's knowledge is largely implicit and taken for granted as a part of everyday life (Vagli 2009 p. 75). Previous research has shown that social work practitioners put great trust in experience, intuition and personal judgment when dealing with the often complex situations encountered in daily practice (Bergmark \& Lundström 2007; Gibbs \& Gambrill 2002; Healy 2009; Munro 20II; Sheppard \& Ryan 2003). To establish routines and habits through learning from experience is indeed one way 
to cope successfully with the daily flow of events and still be able to maintain a sense of security and stability in life (Giddens I984), but a routinized level of action is most likely insufficient in handling the increasing complexity of tasks and in meeting the growing demands of social work practice (Munro 20II).

The present thesis concerns knowledge use and learning in the daily practices of child investigation work; it addresses questions such as: What knowledge is used, in what way and for what purpose? The study is based on a mix of qualitative approaches, basically from ethnography, comprising methods such as participant observations, interviews, reflective dialogues and documentary analysis of case data. Ethnography allows for exploration of naturally occurring processes in situ, offering the potential to provide insight into the much-discussed topic of putting knowledge into practice.

The thesis is organized into eight chapters. Following this introduction, the second chapter addresses the visible changes in and growing demands of the field of professional work. In the third chapter, a theoretical framework is provided, covering central concepts and theories. The fourth chapter considers previous research on knowledge use and learning in social work practice and some challenges identified in the literature concerning the evidence-based movement into social work. In the fifth chapter, the aim and research questions are presented. The sixth chapter describes the research setting, research process and the methodologies that are used in the thesis. The chapter concludes by discussing quality aspects of the study and ethical considerations. The seventh chapter summarizes the four studies comprising the thesis. The final chapter discusses the thesis findings, contributions to knowledge in the field and implications for practice and future research. 


\section{Background}

This ChAPTER SeTs THE scene for the study, providing a brief description of the concept of profession and professional work. The concept of evidence-based practice is thereafter addressed, as it is an important and widespread idea that has influenced a wide range of professional fields, including social work. The chapter ends by providing an elaboration of the "import" of the idea of evidence-based practice into Swedish social work.

\section{Professional work in transition}

Over the course of history, the concept of professionalism has been a matter of considerable dispute and disagreement among researchers, which has led to difficulties in reaching consensus on how to define notions such as professional work, practice and learning (Evetts 20I4; Svensson \& Evetts 2010).

According to a classic position, professions are knowledge-based occupations and professionals are agents and carriers of the knowledge society (Brante 2013). The knowledge needed for practice is attained through systems of instruction and training in a particular field. Examination and other formal qualifications, often in combination with a code of ethics or behavior, are used to legitimate the professional's claim to a particular field. The definition implies that practices are built on scientific principles, and that professionals are experts who apply this scientific knowledge to practice (Abbott 1988). Examples of classic professions include medicine, engineering, science and law.

However, the professional turf and traits tend to change over time (Brante 2013). Concerning the Continental European societies, to which the Scandinavian countries belong, professionalism has historically been closely connected to the state and state bureaucracies (Svensson \& Evetts 20ro) and the development of the welfare sector has advanced a whole new category of professions, such as nursing, teaching and social work (Brante 20I4). Use of the term professional and professionalism has certainly become an attractive attribute that guarantees a particular standard of 
work (Evetts 20I4). Being a professional is associated with the notion of expertise, that is, being competent, accountable and experienced in a specific field (Svensson 20II).

Governments have gradually endorsed the idea of professional accountability and new forms of managerialism have developed, such as new public management, that have entailed pressure toward rationalization and structural changes in many public sector organizations (Hasselbladh et al. 2008). As argued by these authors, new public management is linked to a wider "movement of rationalization" (pp. 45).

Parallel to this movement of rationalization, there is a strong trend toward an "epistemification" of society (Jensen et al. 2012, p. 2), which suggests that people nowadays engage with knowledge in ways that historically have been associated with scientific communities. In line with this, science in general is assumed to promise security, rationality and reason, to some extent replacing the highly influential traditional authorities of the past, such as the church and the family (Brante 2013; Svensson 2010; Trinder 200ob). Basically, with reference to the potential harm policy-makers and professionals might have when intervening in the lives of service users, it is held that their decisions indeed should include ethical considerations, but also be based on evidence (Gambrill i999; Sackett et al. 1996).

The wider accessibility to knowledge published on the Internet and a range of new information and communication technologies are believed to challenge the importance of professionals and their knowledge and expertise (Evetts 20I4; Parton 2008). At the same time, several and various techniques - such as laws and regulations, norms, self-administrated methods and continuous evaluations - have come to be applied to an increasing extent (Hasselbladh et al. 2008). The development and administration of these new techniques and tools tend to be managed by different actors, rather than the profession itself, partially resulting from the shift in focus concerning what tasks are important for increasing work efficiency.

It has been argued that today's managerial preferences link professionals closer to their work organizations, which suggests a gradual movement from an occupational professionalism to an organizational professionalism (Evetts 20Io; Svensson 20I0). In this change, the professional's autonomy is partly replaced by bureaucratic means, including elements such as hierarchy, output and performance measures and standardization (Evetts 2014 p. 44). Also, the growing concern with the gathering, sharing and monitoring of information tends to replace the relational and social aspects of practice by "a database way of thinking and operating" (Parton 2008, p. 253). The transition is believed to encompass a change in the professional's knowledge 
base, from an abstract expert knowledge base (i.e. an epistemic or cognitive aspect) toward organizational competence requirements (Svensson 20II). Organizational professionalism in this sense finds legitimacy in market value rather than public good, and partnership, collegiality and trust tend to be replaced with management, competition and commercialism. The new ways of organizing also cast doubt on the earlier identified four key actors in the development of professions (i.e. practitioners, users, states and universities), suggesting the role of the employing organization as a fifth and increasingly influential actor (Evetts 20Io). Although there is no established link between the organizational changes and weakening of professional values, Evetts (20I4) claims, "organizational techniques for controlling employees have affected the work of practitioners in professional organizations" (p. 47).

In light of the above speculation as to the links between organizational changes and challenges to occupational professionalism, doubts have been raised concerning the value and importance of drawing a sharp line between professions and occupations $^{1}$ (Evetts 20I4; Svensson \& Evetts 20I0). Evetts (20I4) suggests that both social forms (i.e. profession and occupation) share many common characteristics; for example, the strong dependency on organizational environments and that occupational identity is produced via the specific work cultures, training and experience (ibid.). In line with this, I consider social work to be an occupation, and like other occupations it has its specific characteristics, skills, and a specific, professional knowledge base. Similarly, I have chosen to use the terms social worker, practitioner and professional interchangeably with employees in social work.

\section{Evidence-based practice gains ground}

Evidence-based practice has its roots in evidence-based medicine (Cochrane 1972; Sackett et al. 1996), where it was introduced in the early 1990s as a new paradigm for reducing the gap between research and practice (WorkingGroup 1992). The scientific base expected to promote an explicit and rational process for physicians' decision making that deemphasized intuition and unsystematic clinical expertise, ultimately to improve patient safety and the quality of interventions.

1. Brante (2013) claims that it is possible to determine when occupations are not professions and when they have reached professional status. He proposes that the difference between professions, semi-professions and occupations is analytic, not normative, basically arguing that one practice is, to a greater extent, based on a robust scientific core. However, he agrees with the "occupational ambivalence" that new demands in society, such as new public management, might create in the professional landscape. 
Key concepts and principles from evidence-based medicine have had a substantial influence on related professions, but also in fields far beyond their medical origins (Satterfield et al. 2009). However, the labeling of the concept differs. In the educational field, we find references made to evidence-based education or a school based on scientific grounds (Biesta 2007; Davies 1999), while advocates in the criminal justice domain use the expression evidence-based policing (Sherman 1998), and people within caring talk about evidence-based nursing (Blomfield \& Hardy 2000; Estabrooks et al. 2005). In social work, the term evidence-based social work has become established (Gambrill I999).

However, how we should understand the term evidence-based is far from clear, and in combination with the term practice, the understanding is even more farfetched. Kvernbekk (20II) declares that the concept actually comprises three words: evidence, based and practice, and in order to clarify the notion of evidence-based practice, we need to take a closer look at each of these three terms. If we start with the concept of evidence, it is undoubtedly ambiguous and widely contested (Foss Hansen 20I4). Kvernbekk (20II), however, defines evidence as something that supports a hypothesis, that is to say, something that justifies our belief in a hypothesis or disconfirms a hypothesis. Thus, what counts as evidence depends on the question or the problem we are trying to solve (Hammersley 2009). Data alone (such as facts, propositions, narratives) are not evidence, but may become evidence depending on the formulation of a hypothesis. "In other words, evidence is made, not found" (Kvernbekk 2orI, p. 53I). Thus, all kinds of data, propositions or narratives can constitute evidence if they are related to a hypothesis. Somewhat in line with this is Eraut's (2004a) statement that knowledge will be publicly accepted as evidence if it is believed to be true or to have a reasonable probability of being true, either because it is based on research or on arguments from practical experience.

The term based in evidence-based practice is commonly understood as deduction from more general knowledge, which suggests that practice could and should originate from a foundation of evidence, or more explicitly be based on research (Kvernbekk 20II). Thus, there is a belief that research will be able to tell us "what works" (Biesta 2007; Kvernbekk 20II). Yet a hypothesis or a practice is not based on evidence, but instead supported by it (Kvernbekk 20II).

Lastly, practice is a complex social activity with its own aims and standards (Kvernbekk 20II). A certain practice is not primarily concerned with attempting to justify a hypothesis or theory, but with effectiveness (Trinder 2000a). 
Kvernbekk's elaboration on the concept of evidence-based practice accords well with the original widely quoted definition from evidence-based medicine, in which evidence-based practice is defined as: "the conscientious, explicit, and judicious use of current best evidence in making decisions about the care of individual patients" (Sackett et al. 1996). The definition was followed by the argument that both the professionals' expertise and external evidence are needed to qualify a certain practice as evidence-based, suggesting that external evidence can inform, but never replace, professional expertise.

Among most researchers there is considerable agreement that the notion of evidence-based practice involves a combination of three knowledge sources: the client's values, preferences and experiences, professional expertise ${ }^{2}$ and the knowledge derived form research. This tripartite evidence model was originally pictured as three overlapping circles, where the intersection was represented by evidence-based practice (Figure I). Later, allegedly more elaborate versions of the evidence model frame "clinical expertise" or "professional expertise" as the centralizing unit for successful implementation of evidence-based practice, besides adding a fourth component of contextual factors (e.g. Haynes et al. 2002).

Although the definition of evidence-based practice has been adjusted over the years, it is possible to distinguish between two different conceptualizations regarding the nature of evidence-based practice in the literature (Bergmark et al. 2orr;

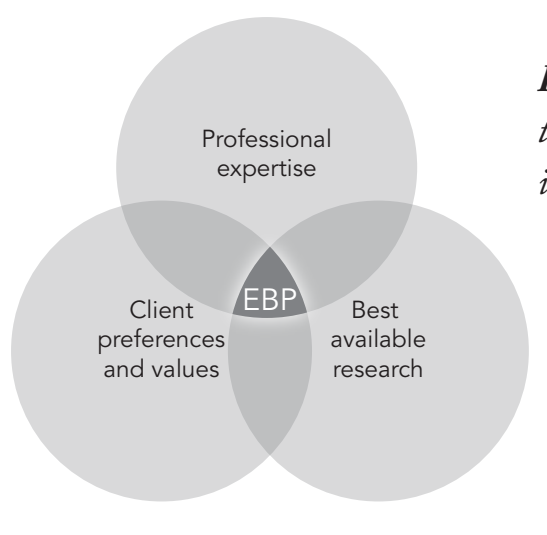

Figure 1. A common conceptualiza-
tion of evidence-based practice as an
interplay of three knowledge sources

2. Professional expertise can be defined as "knowledge and experience acquired through work and developed in education (Oscarsson 2009). The concept will be elaborated in the following description of key concepts. 
Broadhurst et al. 2010; Olsson 2007). The first view is concerned with specific interventions, treatments or policies and to what extent these have empirical support regarding certain outcomes. This view has been referred to as a rational choice model that focuses on evidence-based methods and their outcome (Soydan 20ro). According to this view, the implementation of standards and practice guidelines is thought to be an important means of developing both people and practice (Timmermans \& Berg 2003). Preferably, these standards and guidelines should be derived from randomized controlled trails, which represent the highest evidence order and have become the new gold standard (p. 27).

The other view relates to the nature of professional decision making and how research-based knowledge is used in this process (Olsson 2007). From this perspective, evidence-based practice is not merely the application of a method, but a process in which practitioners utilize different knowledge sources to improve decision making and ultimately service users' safety (Gray et al. 2009, p. I). This latter view has also been referred to as a critical appraisal model for evidence-based practice (Sackett et al. 2000). According to this conceptualization, the practical application of evidence-based practice is a process comprising five steps:

I. Converting one's need for information into an answerable question.

2. Tracking down the best external evidence with which to answer the question.

3. Critically appraising that evidence for its validity, effect and applicability.

4. Appling the results of this appraisal to practice and policy decisions, involving clients in making decisions and considering other application concerns.

5. Evaluating the effectiveness and efficiency in carrying out Steps 1 to 4 and seeking ways to improve them in the future (Sackett et al. 2000, pp. 3-4).

There tends to be an underlying democratic vision of this model. Implicitly, Sackett et al. (2000) touch upon a conceptualization of evidence-based practice as a learning process. Such an approach is in line with the view of knowledge use as a process of reflection and learning - a view that is explored in the present thesis. 
Furthermore, Haynes et al. (2002) declare that evidence-based practice actually "is a guide for thinking about how decisions should be made" (p. 36). Thus, certain authors also see doing evidence-based practice as participatory and as a way to empower professionals and service users by bringing practice closer to research:

The philosophy and process of evidence-based practice as described by its originators is a deeply participatory, antiauthoritarian paradigm that encourages all involved parties to question claims about what we know. It pits Socratic questioning against those who prefer not to be questioned (Gambrill 2006, p. 352)

Considering this review of definitions of evidence-based practice, it seems fair to say that evidence-based practice is an elusive concept. Even among experts, there is a lack of consensus about the definition of the term (Bohlin \& Sager 2orr; Olsson 2007), which most likely opens the way for different actors to create their own interpretation of the phenomenon and how to implement it.

Although evidence-based practice is not of focal interest in the present thesis, I have described it here because it is an important and widespread idea that has largely permeated a wide range of professional fields, including social work. It is also important here because it has brought to the forefront central issues about the relations between research and practice and the use of different forms of knowledge in professional practice that indeed are of interest in the thesis.

\section{The import of evidence-based principles into Swedish social work}

In Sweden, the proponents of evidence-based social work are primarily found among central and local decision makers (Soydan 20Io), in contrast to the strong professional influence in the US (Bergmark et al. 20II). Professionals put great trust in the central state to support the implementation of evidence-based social work (ibid.), and the Swedish movement of efforts to use scientific knowledge in practice has thus far been "a top-down, policy-driven process" (Soydan 2010, p. I90).

Oscarsson (2009) emphasizes that the aim to develop evidence-based practice was (and still is) part of the Swedish Government's broader attempts to reinforce the quality of social services. It was not until the late I99os that evidence-based practice 
was apparent in Swedish social work ${ }^{3}$ (Bergmark et al. 2oII; Soydan 20Io; Tengvald 2008). Prior to the evidence-based paradigm, the Swedish Government had made great efforts to support the development of transparent practices with registers, quality indicators, nomenclature, open comparisons and user surveys under the banner of knowledge-based practice (Tengvald 2008). In 1992, the National Board of Health and Welfare (the national government agency for the supervision and monitoring of healthcare and social services) launched the Centre for Evaluation of Social Services (cus), which was in charge of research utilization and evaluation within the social services. In 2004, cus was replaced by the National Institute for Evidence-Based Social Work Practice (IMs), the aim of which is to support the development toward evidence-based social work. Today, IMs is dissolved and its activities lie within the National Board of Health and Welfare's regular organization.

As indicated earlier, Sweden has swiftly adopted the evidence-based principles and new managerial preferences, such as new public management (Morago 2006). A starting point for different stakeholders' growing interest in evidence-based practice was a proposal that was finalized in 2008 (sOU 2008:68). The proposal outlined several actions toward a more evidence-based social work, for example: increased research and evaluation studies of practice results, quality and efficiency; training for follow-up strategies, skills to search and use research results; improved instruments for documentation, systematization, dissemination and an environment for social workers' own practice experiences to be accredited; enabling new forms of user involvement and user input (pp. Ioo-I2). Moreover, the proposal declared a broad definition of evidence-based practice, which accounted for both professional expertise and service users' priorities and experiences (Jerdeby, 2008; Socialstyrelsen 20II). The Government's central role in the implementation process can be confirmed by the extensive public funding, which has increased over the years. A peak occurred in 2010 when the Swedish Association of Local Authorities and Regions (an employers' organization and an organization that represents and advocates for local government in Sweden, of which all of Sweden's municipalities, county councils and regions are members) received over so million euro in order to implement the recommendations in the proposal.

A common strategy in most municipalities working toward more evidencebased social work has been to develop R\&D centers (Hanberger et al. 20II). Besides

3. I would add, parenthetically, that social work has traditionally been held to be an authoritybased practice lacking a solid scientific ground (Gambrill 1999; Soydan 2010). First in 1977 a political decree was enacted stating that Swedish social work should be an academic subject with its own research area. 
working with education, information and boundary-crossing activities to develop professional expertise, a majority of the centers are used to reinforce the implementation of evidence-based methods and guidelines in the social care services. While these centers create important arenas between municipalities, regions and universities as well as support knowledge diffusion, a recent report (Statskontoret 2014) indicates that they only partially influence changes in actual practice and that social care services still have a long way to go before achieving more structured processes of knowledge development. A final comment worth mentioning is that none of the legal regulations refers to evidence-based practice (sou 2008).

In all, the rapid changes in society and increasing demands for practice to be based on the most up-to-date and trustworthy knowledge suggest that the existing knowledge structures in many professions, social work included, are challenged and in need of modernization. It follows that professionals' learning and the renewal and extension of professional capacities have been stressed in the public debate. 


\section{Theoretical framework}

This chapter introduces the central concepts and theories that have been used in the four studies comprising this dissertation.

\section{The concept of knowledge}

Unpacking the concept of knowledge is not an easy undertaking. Knowledge is a multifaceted phenomenon and the understanding of knowledge, like all phenomena, must be related to the time and context in which it is located. Numerous attempts have been made over the years to define the concept of knowledge and delineate different forms of knowledge.

Here I will use Aristotle's three knowledge forms as a point of departure: episteme, techne and phronesis (Artistotle 1967). Aristotle's notion of episteme refers to knowledge connected to science and research, techne denotes context-dependent, practically applied knowledge, characterized by a combination of action and reflection, and phronesis is knowledge developed in interaction with others, and described as an ethical sensitivity or wisdom (Gustavsson, 2004). Somewhat simplified, episteme may be seen as explanatory knowledge, techne as action-related knowledge and phronesis as knowledge that can guide the individual in taking the best course of action.

Another important distinction is that between knowing-how and knowing-that (Ryle 1945). These forms of knowing or knowledge are acquired and accumulated through different learning processes. Knowing-how is constructed from experience and doings. It is a form of procedural knowledge that is realized in what an individual does, that is, in action. This knowledge is often tacit and embedded in the individual, but also institutionalized in organizational routines and processes. Knowing-that signifies explicit and codified knowledge of facts (ibid.) based on a systematic process of knowledge creation, and validated in accordance with scientific procedures and standards. 
A third and more pragmatic perspective on knowledge is provided by Lindblom and Cohen (1979). They posit that knowledge is "knowledge to anyone who takes it as a basis for some commitment or action" (p. I2), regardless of whether this knowledge is true or false, is based on scientific procedures or is the result of experiences. These authors also expand the distinction between theoretical and practical knowledge by distinguishing between social science knowledge and ordinary knowledge.

Social science knowledge is related to some degree of confirmation, which implies that the knowledge has been exposed to some kind of "testing," such as a scientific process, thus having obtained a certain degree of "truth status" (p. I2). In contrast, ordinary knowledge is seen as knowledge related to thoughtful speculation and analysis, casual empiricism, and common sense, including both conscious and unconscious beliefs and values held by an individual (Lindblom \& Cohen 1979). Distinctive features of ordinary knowledge include that it is highly context-specific, personal and created through social interaction.

Lastly, it is relevant to also mention Eraut's (2000; 2007) epistemology of practice, in which he makes a distinction between a personal and cultural perspective on knowledge. The cultural perspective concerns knowledge creation as a social process, which may yield both codified and uncodified knowledge. The personal perspective on knowledge is defined as a cognitive resource that incorporates an individual's capabilities (what the individual can do) and the understandings that inform these capabilities, including codified knowledge in its personalized form. A distinctive feature of personal knowledge is its focus on the use of knowledge. It includes knowhow in the form of skills, practical wisdom and expertise, but also self-knowledge, attitudes and emotions (Eraut 2007, p. 406). In contrast, cultural knowledge focuses on the recognition of knowledge, which can be found in the practices and discourses of a profession, for instance in procedures, beliefs, norms and behaviors.

Although knowledge is a multifaceted phenomenon and several definitions and typologies have been proposed in the literature, a recurrent conceptual distinction is the one made between scientific or research-based and practice-based knowledge. These two knowledge forms will be elaborated on next.

\section{Two different but complementary knowledge forms}

Research-based knowledge (also referred to as scientific knowledge) is derived from empirical research findings as well as from concepts, theories, models and frameworks used in research to understand and explain various phenomena. Research- 
based knowledge is generated in a structured and systematic process, which usually begins with a thorough analysis of the problem under study before research questions and the issue to be investigated are formulated. The production of researchbased knowledge is often separated from the later practical application and use of the knowledge that is produced.

Research-based knowledge is explicit and codified, primarily formulated in texts, and it is assumed to be generalizable and context-independent (e.g. Biesta 2007; Ellström 2009). In contrast, practice-based knowledge is most often implicit (tacit) (Polanyi 1966; Schön 1983), but may also be articulated in a practice setting (Zollo \& Winter 2002).

While research-based knowledge rarely provides quick solutions to problems, practice-based knowledge predominantly serves to solve the problems that occur in everyday life and work. Practice-based knowledge is viewed as knowledge that is comprised of action-result or means-ends linkages (Kvernbekk 1999). Practice-based knowledge can be manifested in skills, acquired and used in action and, thus, is thought to play an important role in informing practice through its primary focus on problem solving (Barkham \& Mellor-Clark 2003). Key characteristics of researchbased and practice-based knowledge are described in Table I.

It may be worth mentioning here that attempts have been made to use the distinction between these two knowledge forms to distinguish between two forms of evidence, that is, between research-based and practice-based evidence (Barkham \& Mellor-Clark 2003; Eraut 2004a). The former is related to satisfying the scientific criteria that are formulated in a specific area of research, while the latter refers to knowledge that is recognized and considered as valid by the relevant profession and is applied in accordance with the criteria expected by experts within that professional practice (Eraut 2004a). Practice-based evidence is considered to be knowledge "that works" in practice, having gradually been built up from personal experience (Kvernbekk 1999). This can be contrasted to he notion of the "what works" agenda that is commonly associated with evidence-based practice (e.g. Biesta 2007; Kvernbekk 2011).

Importantly, two things should be mentioned regarding the distinction made between research-based and practice-based knowledge. First, it is a theoretical distinction, and as such basically useful in illustrating certain aspects of knowledge. Second, the line between the different knowledge forms is sometimes overstated or drawn too sharply, which causes an undesirable and unnecessary polarization. In practice, the different forms of knowledge often are intertwined and may be indis- 
Table 1. Key characteristics of research-based and practice-based knowledge

\begin{tabular}{|c|c|c|}
\hline Charecteristics & $\begin{array}{l}\text { Research-based } \\
\text { knowledge }\end{array}$ & $\begin{array}{l}\text { Practice-based } \\
\text { knowledge }\end{array}$ \\
\hline $\begin{array}{l}\text { Rationale for } \\
\text { knowledge } \\
\text { development }\end{array}$ & $\begin{array}{l}\text { Obtaining improved } \\
\text { understanding or explanation } \\
\text { of problems }\end{array}$ & Finding solutions to problems \\
\hline $\begin{array}{l}\text { Desirable } \\
\text { knowledge } \\
\text { attributes }\end{array}$ & $\begin{array}{l}\text { Possible to generalize } \\
\text { Accessible to and understandable } \\
\text { by others } \\
\text { Public, explicit, codified } \\
\text { knowledge } \\
\text { Primarily expressed in writing }\end{array}$ & $\begin{array}{l}\text { Context-specific, hands-on } \\
\text { use in concrete, everyday } \\
\text { situations } \\
\text { Unique, personal, usually tacit } \\
\text { knowledge } \\
\text { Expressed in action }\end{array}$ \\
\hline $\begin{array}{l}\text { Knowledge } \\
\text { diffusion }\end{array}$ & $\begin{array}{l}\text { Accessible and available } \\
\text { Easy to share }\end{array}$ & $\begin{array}{l}\text { Embedded in individuals } \\
\text { and organizations } \\
\text { Difficult to share }\end{array}$ \\
\hline $\begin{array}{l}\text { Context } \\
\text { dependent }\end{array}$ & Not generally & Yes \\
\hline $\begin{array}{l}\text { Other terms } \\
\text { in use }\end{array}$ & $\begin{array}{l}\text { Scientific knowledge } \\
\text { Research-based evidence } \\
\text { Theoretical knowledge } \\
\text { Codified or explicit knowledge } \\
\text { Know-that, Know-why }\end{array}$ & $\begin{array}{l}\text { Ordinary knowledge } \\
\text { Practice-based evidence } \\
\text { Everyday knowledge } \\
\text { Tacit or implicit knowledge } \\
\text { Know-how }\end{array}$ \\
\hline $\begin{array}{l}\text { Means to } \\
\text { develop } \\
\text { knowledge }\end{array}$ & $\begin{array}{l}\text { Learning-by-studying } \\
\text { Empirical studies } \\
\text { Theorizing }\end{array}$ & $\begin{array}{l}\text { Learning-by-doing } \\
\text { Pragmatic activities } \\
\text { Experiencing }\end{array}$ \\
\hline
\end{tabular}

tinguishable from the point of view of the individual. Under different circumstances either knowledge form may dominate, depending on factors such as the type of activity the individual undertakes or the profession. Dewey (I9I0) argues that theoretical knowledge and practice-based experience are the making of each other, and therefore neither one should be valued higher than the other. Instead, these different forms of knowledge are used and interwoven in the practical activities of human beings. 


\section{The concept of knowledge use}

Knowledge use (also referred to as knowledge utilization) has been defined as strategies designed to put scientific knowledge to use effectively, such as to solve a problem in a practical setting (Backer I99I, p.225).

Originally, knowledge use was assumed to occur when knowledge, in the form proposed by a researcher, was used in a way that led to some specific action (intended or unintended) or decision (Larsen 1980). A basic assumption underlying this understanding of knowledge use was that a rational decision maker or actor would act on research results. This approach to knowledge use mirrors the research field's historical roots in rational actor theories, theories of bureaucracy and decision-making theories (Rich 199I).

More recent understandings of the concept of knowledge use recognize that knowledge influences thinking as well as action, and that a degree of adaptation, modification and selection of the knowledge may take place in the utilization process (Knorr-Certina 198I). Knowledge use has been conceptualized as "an interactive process influenced both by time and context" (Larsen 1980, p. 426), which suggests that knowledge that is considered appropriate and relevant at one time and place might be deemed inappropriate and irrelevant at another. Besides time and context, additional features that have been thought to influence the use of knowledge are the characteristics of the research knowledge (e.g. qualitative or quantitative studies), organizational structures and the accessibility and the interaction between researchers and potential users (Amara et al. 2004; Nutley 2007; Weiss \& Buchuvalas 1980). Further, the individual's attitudes, values, beliefs and motives influence knowledge use (Eraut 2004b).

Three types of knowledge use are commonly distinguished in the literature: instrumental, conceptual and symbolic use (Amara et al. 2004; Weiss 1979). Instrumental use involves applying research results in specific, direct ways that yield concrete actions or decisions (Larsen 1980). Conceptual use of knowledge assumes that knowledge is used for general enlightenment, such as providing new concepts, ideas and perspectives that might be useful but in a more indirect way. Lastly, symbolic use involves using research to legitimate or sustain a certain activity or decision (Amara et al. 2004). This type of knowledge use has also been referred to as a "political model" (Weiss 1979, p. 429), in which decision makers are unlikely to be receptive to new evidence or knowledge that clashes with their predetermined idea. Instead, some studies have shown that research knowledge is used as "ammunition" 
for certain prevailing ideas or as a reason and means to maintain previous practice or stick to a decision (ibid.).

While studies of knowledge use have suggested that there is a gap between the culture of science and the culture of practice that may explain the often observed low levels of instrumental knowledge use (Rich 1991; Weiss \& Buchuvalas i980), KnorrCetina (198I) claims that this may not be due to discrepancies between science and practice, or related to the attributes that characterize these different communities. Rather the relatively few occurrences of instrumental knowledge use may partly be attributed to the temporal and contextual nature of practical action. In many situations, the evidence available to us may be insufficient to determine what beliefs we should hold in response to it, or more specifically, science is inconclusive in itself and we cannot know whether the findings are correct, and therefore we tend to use practical circumstances to compensate for this shortcoming.

Practical interests are claimed to continually override existing rules from social science (Knorr-Cetina I98I, p. I49). Standard models of knowledge use or rule application are often problematic in practical settings. Rather, we tend to combine rules and knowledge into meaningful patterns of practical action. This would thereby suggest that even carefully structured and planned implementation processes might fail due to the "self-structuring" nature of practice. Rich (I99I, p. 326) argues that the incomplete search for and use of knowledge in a bureaucratic setting may actually be found in the organizational procedures and rules, standard operating procedures and the needs and constraints of the bureaucratic organization.

To sum up, knowledge use tends to be a complex process that is influenced by social, organizational and professional factors. According to Ellström (2009), knowledge use may be regarded as an encounter between explicit, research-based knowledge (or for example results from an evaluation) and implicit knowledge that is linked to a specific action. From this perspective, knowledge use may be considered in terms of a learning process. The instability or indeterminacy (uncertainty) that may arise when different knowledge sources are used creates a potential for learning (Dewey 1910; Knorr-Certina 198I). Thus, disorder, uncertainty or doubt $^{4}$ may be conducive to change. In the following, the processes of knowledge use will be explored from a learning perspective.

4. Pierce $(1905$, p. 168) claims that doubt is 'the privation of a habit' and as such offers a learning opportunity and basis for practice change. 


\section{Professional learning at work}

The concept of learning has traditionally been related to formal education, and it is only since the beginning of the r99os that an interest in learning at work has developed (Tynjälä 2008). In comparison to school-based learning, which is foremost based on individual activities and aims at the acquisition of non-contextual general skills, the learning and training that takes place at work is, to a greater extent, socially shared and develops situation-specific competencies (Hager 2004; Marsick \& Watkins 1990). More specifically, workplace learning is developed in and through the work process itself, but also through mentorship and coaching (Evans in print). This form of learning entails the acquisition of practical knowledge and the understanding of what means (actions) may lead to intended results (Kvernbekk 1999).

\section{Learning as transformations between tacit and explicit knowledge}

The close interplay between learning and action often makes it hard for practitioners to recognize that any learning is taking place at all. Over time, work experiences tend to become embedded in ordinary knowledge and increasingly tacit, which makes this knowledge difficult to share with others (Eraut 2004b). However, if individuals' knowledge and skills remain tacit there is a risk of underestimating the individual's competence and his/her contribution to the organization. There is also a risk that the development of tacit knowledge over time will lead to routines. The individual starts to take shortcuts without considering that circumstances change, which evidently risks a loss of effectiveness (ibid.).

Nonaka and Takeuch (1995) suggest that the very notion of learning actually means transformations of knowledge based on interactions between tacit and explicit knowledge. Although codification efforts to develop and transfer both knowingthat and knowing-how may provide an opportunity to expose action-result links to critical reflection (Zollo and Winter 2002), to verbalize tacit knowledge and learn from it is recognized as difficult and something that often requires organized forms of knowledge transformations (Eraut 2000; Evans in print; Nonaka \& Takeuchi 1995; Zollo and Winter 2002).

Lindblom and Cohen (1979) argue that the mere focus on, attention to and awareness of everyday practices allows for knowledge to be articulated and refined. However, in line with other researchers (e.g. Alvesson \& Spencer 20I2), they contest the notion that practice is usually organized for reflection activities. More often human interaction is used for problem solving, which characterizes a problem-solving 
process that creates highly usable knowledge, although, often implicit and thus not open to questions and examination (above described as ordinary knowledge).

Lindblom and Cohen's (1979) argument that the special attention to and awareness of everyday practice may enable the articulation and refinement of ordinary knowledge can be related to the notion of deliberate practice. The concept of deliberate practice refers to activities for training, professional learning and social problemsolving that are designed to improve specific skills or the performance of particular tasks (Ericsson et al. 1993). For these activities to be efficient, some specific characteristics are required, including feedback, a high level of individual motivation and well-designed tasks. Feedback (e.g. through evaluations of professional performance on certain tasks) is believed to be the most important individual requisite for efficient learning. Without feedback, performance improvement is only minimal even for highly motivated learners (ibid., p. 367).

Also, the notion of knowledgeable practice comprises the special attention to and awareness of everyday practice that Lindblom and Cohen (1979) claim is of importance to enabling the articulation and refinement of ordinary knowledge. A key feature of knowledgeable practice is "the exercise of attuned and responsive judgment when individuals or teams are confronted with complex tasks and often unpredictable situations at work" (Evans in print). Hence, when carrying out different work tasks, practitioners should be aware of the knowledge and judgments that underpin the managing of work. Often this knowledge has to be reconsidered to allow for changing practices at work (ibid.). Then again, this is easier said than done and is dependent on the extent to which the organization can establish a workplace that is organized not only for production but also for learning (Billett 200I, 2004; Ellström 20II; Eraut 2007; Rainbird et al. 2004).

Ericsson et al. (1993) differentiate between three general types of activities that are found at the workplace: work, play and deliberate practice. They posit that although work activities offer learning opportunities (cf. Billett 2002; Ellström 200I, 20II; Eraut 2000, 2007; Fuller et al. 2004), they are far from optimal in comparison to deliberate practice, which allows for repeated experiences and incremental improvements in response to knowledge of results and feedback.

Next, by turning to Ellström's (200I, 2006) framework for workplace learning, I will address processes of knowledge use and learning in work from the perspective of cognitive action theory. 


\section{Two modes of learning in work}

A basic assumption behind Ellström's (200I, 2006) model of learning in work is that different work tasks require different degrees of awareness that are described on a continuum, from being conscious and deliberate to being routinized and performed with little or no conscious control. A distinction is made between four levels of action and knowledge: (I) skill-based or routinized action based on implicit knowledge about actions and their results, (II) rule-based action based on procedural knowledge stored as rules ("know-how"), (III) knowledge-based action and (IV) reflective action, which both entails codified, theoretical and explanatory knowledge. Learning is assumed to occur as an interplay between routinized and knowledge-based or reflective levels of action, or, in other words, as transformations between explicit and implicit knowledge. Ellström's model is in certain respects similar to the model of organizational learning proposed by Zollo and Winter (2002). The latter authors conceptualize learning as an interaction between three mechanisms: (I) accumulation of experience (tacit knowledge) through more or less routinized actions; (2) articulation of tacit knowledge, for example through sharing and comparing individual experiences in discussions with colleagues; (3) codification of knowledge (e.g. through documentation).

Based on the idea that the four levels of action in Ellström's (200I; 2006) model entail different levels of knowledge use and reflection, he makes a distinction between two different modes of learning: an adaptive and a developmental mode of learning. The mode of adaptive learning focuses on the formation of skills for handling routine tasks or problems that occur in daily practices. The learning is primarily based on experience and can ideally yield efficient task performances that are stable over time (cf. the notion of deliberate practice discussed above). This way of transforming knowledge into practice is thought to be indispensable for mastering and performing many work tasks well and for solving different types of problems that are encountered in daily practices.

In contrast, the mode of developmental learning originates from encountering new, unexpected or in some way problematic situations (disturbances; cf. Dewey, I9Io), and is assumed to be triggered when individuals or groups within an organization start to reflect on and question their habitual and routinized ways of acting. Thus, through a developmental mode of learning they may develop new knowledge and ways of handling tasks, situations and the often complex problems involved in a job (Ellström 20II). 
Related to processes of knowledge use, the developmental mode of learning is a way to conceptualize the process of questioning current practices and search for new knowledge. It can be described as a process in which tacit knowledge becomes articulated and codified (i.e. de-contextualization of knowledge). The adaptive mode of learning concerns the process of mastering new ideas and practices. It can be characterized as a movement in which explicit knowledge and experiences become increasingly tacit and embedded in ordinary knowledge as common sense (i.e. contextualization of knowledge).

Taken together both adaptive and developmental modes of learning are central to knowledge use and workplace learning, and thereby I assume involved in the becoming of a skilled professional. Becoming a skilled professional, or with a commonly used term: an expert, involves the ability to act knowledgeably, deliberately and reflectively in a given situation (Evans in print). In the next section, I will therefore consider the meaning and significance of professional expertise in relation to knowledge use and learning at work.

\section{Reflection and intuition in professional expertise}

Professional expertise is the result of knowledge that is built up over many years through conscious and unconscious learning based on the accumulation of experiences and wisdom (Sadler-Smith \& Sheffy 2004, p. 82).

The notion of professional expertise has become a basic concept in several efforts to conceptualize evidence-based practice (e.g. Sackett et al. 1996). Expertise concerns a professional's ability to put theoretical knowledge into practice and make use of and control the work systems and procedures (Evetts 20I4). Hence, a distinguishing feature of expertise is the ability to use knowledge rather than being related to how much one knows (Schmidt \& Bushuizen 1993).

Sadler-Smith and Sheffy (2004) suggest that professional expertise involves two seemingly contradictory capabilities: reflection (or rational thinking) and intuition. While the power of conscious reasoning and deliberative analytical thought (i.e. reflection) is considered a professional and highly valued attribute in many Western societies (Easen \& Wilcockson, 1996; Sadler-Smith \& Sheffy 2004), intuition has the potential to inform judgments when outcomes are difficult to predict through rational means (Sadler-Smith 20r4; Sellbjer \& Jenner 20I2) or when the professional has developed a tacit understanding of situations that allows abandonment of ex- 
plicit rules and guidelines (Eraut 2000). I will briefly describe these individual capabilities.

To begin with, reflection can be described as a mechanism to translate experience into learning by examining one's attitudes, beliefs and actions, to draw conclusions to enable better choices or responses in the future (Dewey I9IO). As advocated by Dewey, reflection is an activity of deliberating on the past. Eraut $(2004 \mathrm{~b}$, p. 25I suggests that when experiences are distinguished from the daily flow of events ${ }^{5}$, brought into the area of conscious thought and accorded attention, discussed and reviewed, it is only then that they become meaningful.

Many problems in the real world require that the individual make some kind of diagnosis to depict and understand a situation and act upon it in an appropriate way (Schmidt \& Bushuizen I993, p. 206). Thus, a certain kind of reasoning must take place if we are to reach justified decisions about what we ought to do, also referred to as practical reasoning or discretion (Molander \& Grimen 20IO, p. I7I). This activity is considered to be both a cognitive activity (i.e. reflection) and a space for making decisions and choices based on the results of this cognitive activity. The cognitive activity is referred to as epistemic discretion and may result in conclusions about what is true, right or good (cf. phronesis). The other form of discretion is referred to as a structural aspect and represents a delegated liberty and area where it is possible to choose between permitted alternatives of action (ibid.).

While individuals constantly interact with the environment in order to understand a situation or problem and effect changes that would not otherwise occur, reflective thinking is not achievable in all situations due to factors such as shortage of time and the role of uncertainty (e.g. Eraut 2000). An alternative explanation is needed for the quick, many times excellent judgments made routinely in everyday practice. Relying upon intuition is proposed as one way to cope with uncertainty and complexity (Kahneman 20II; Klein 1999; Sadler-Smith 20I4; Sadler-Smith \& Sheffy 2004).

Intuition can be described as "a capacity for attaining direct knowledge or understanding without the apparent intrusion of rational thought or logical inference" (Sadler-Smith and Sheffy 2004, p.77). In other words, intuitive judgments are believed to be arrived at by an informal and unstructured mode of reasoning (Kahneman \& Tversky 1982) and they enable us to size up a situation quickly (Klein 1999). Intuitive knowledge is thought to be based on the human ability to generalize on

5. Weick and Westley (1996, p. 449) define an event as "a moment in a process," which suggests that an event actually is an experience. 
incomplete grounds (Dewey I9IO; Sellbjer \& Jenner 20I2) and to be a form of knowing, which is an alternative or possibly a complementary form of cognition (SadlerSmith \& Sheffy 2004). 


\section{Previous research}

THE FOllowing CHAPTER DESCRIBEs previous research on knowledge use and learning in social work practice of relevance to the present study.

\section{What counts as valuable knowledge for practice?}

Many researchers have discussed the nature and form of knowledge used in social work practice (e.g. Munro 20II; Osmond \& O'Connor 2006; Pawson et al. 2003; Rosen 1994; Trevithick 2008). Much of this research has established that practitioners put great trust in experience, intuition and professional judgment when dealing with the often complex situations encountered in daily practice. Indeed, numerous studies have shown social workers' widespread use of tacit knowledge (Nordlander 2006; Osmond 200I; Vagli 2009; White 1997) and modest interest in appropriating and using knowledge from outside the practice setting (Bergmark \& Lundström 2007, 2008; Gibbs \& Gambrill 2002; Healy 2009; Sheppard \& Ryan 2003; Trinder 2000 b; Webb 200I).

The established "truth" concerning practitioners' scarce interest in knowledge created outside the practice setting does not seem to hinder recent evidence-based approaches that are committed to scientific methods and see them as the best way of developing reliable knowledge (Gray et al. 2009). There are several examples of evidence typologies used to rank different approaches to producing evidence (for an overview, Foss Hansen 20r4; Morago 2006). Systematic reviews of randomized controlled trials are usually placed at the top of these hierarchies. This type of experimental study means that the researcher actively intervenes to test whether a treatment or some type of intervention is more efficacious than another option. The researcher manipulates one or more independent variables that are assumed to have a causal effect on the dependent variable (outcome). Randomization means that the research subjects are divided equally between the intervention and control groups, thereby controlling for confounding factors. Observational studies (lacking manipulation by the researcher), case studies, narrative literature studies and expert opin- 
ions occupy progressively lower rankings on the evidence order. However, there is a trend toward using broader definitions of evidence and an increased acceptance of other types of study designs (Morago 2006).

\section{Use of research in practice}

The supposed gap between research and practice has undoubtedly been a recurring theme in research on the evidence-based project (Bergmark et al. 20II; Marsh \& Fisher 2008; Mullen et al. 2008). It has been suggested that the limited use of research can be attributed to social work being a traditionally authority-based practice, which lacks a solid scientific ground (Gambrill 1999; Soydan 2010). But another suggestion is that there is a paucity of relevant social work research, uncertainty concerning the nature of evidence, and difficulty in interpreting and applying it in a complex practice setting (Barratt 2003; Bergmark \& Lundström 2006; Bohlin $\&$ Sager 2orI). In line with these latter arguments, the Swedish Board of Health and Social Welfare argues that the problem of underuse can be ascribed, at least partially, to researchers' failure to generate knowledge that is useful to the field (Socialstyrelsen 20II).

Studies have discussed the underuse, or even non-use, of research-based knowledge in policy and practice (e.g. Nutley et al. 2007; Osmond \& O'Connor 2006). Time constraints, lack of resources in the system and the uniqueness and complexity of each case suggest that practitioners make pragmatic decisions rather than engaging in a critical appraisal process, as described in the evidence-based model (Lindquist 2012; Lipsky 1980; Munro 2010; Otto et al. 2009). White (2009) argues that the use of popular ideas, everyday theories and experiences actually "excuses" social workers from the need to justify their actions based on more verified knowledge, such as research. In Sweden, the much-used method of supervision by outside consultants, who also tend to provide practitioners with tools and popular models for managing work, has been suggested as a further reason for the limited use of research (Bergmark \& Lundström 2002).

Despite the many studies indicating limited use of research in social work practice, Osmond and O'Connor $(2004 ; 2006)$ warn against coming to hasty conclusions about the matter. They find that research is indeed used in practice, but without appearing to be comprehensive or thoroughly understood. They suggest that this might be caused by practitioners' difficulties in articulating what they know (see also Nordlander 2006). Furthermore, it has been shown that practitioners in fact use research 
and theories, but in an a posteriori fashion for legitimizing reasons (e.g. Broadhurst et al. 20Io; Nutley et al. 2007; Wastell \& White 2009; Weiss I979). In other words, research is used to explain clients' situations or provide support for one's own beliefs and decisions. In line with this, it has been recognized that easy adoption of research is not likely to occur. Rather, an adaptation takes place (Barratt 2003; Sheppard et al. 2000), a process in which research is reformulated and personalized, often through social interaction, before it becomes practically applicable (ibid.). This way, theory that professionals find useful becomes part of common-sense knowledge and treated as self-evidently true (e.g. attachment theory) (Wastell \& White 2009).

\section{Knowledge for decision making in practice}

So, what knowledge has been shown to be useful in social work practice? While there are studies showing extensive use of legal regulations among social workers (e.g. Brante et al. 20I4; Sheppard \& Rayan 2003), it has been established that a basic source for generating knowledge for decision making is the client and his/her life situation (e.g. Munro 20II; Nordlander 2006; Osmond 200I). The importance of building client-professional relationships in social work practice has been well documented in previous research (Broadhurst et al. 20I0; Ferguson 20I4; McCracken \& Marsh 2008; Van de Luitgaarden 20II). Nordlander's (2006) study on social worker's knowledge use in investigation work showed that once facts were established, social workers tended to choose interventions that had the capacity to lead to desirable results. He suggests that social workers value knowledge that is instrumentally useful for quick action and decision making. It should be noted that Nordlander's study did not address instrumental research use, instead his study showed that practice was based on instrumental use of knowledge in general.

Various knowledge classifications have been developed for social work practice (e.g. Drury-Hudson I999; Osmond 200I; Pawson et al. 2003; Trevithick 2008). A1though it is not possible to provide a complete review here, some illustrations can be made about the diversity of knowledge forms that have been shown to inform practice. One example is Drury-Hudson's (I999) exploration of what knowledge social workers draw upon in child investigation work. The study identified five basic knowledge forms - theoretical, personal, empirical, practical and procedural knowledge - that make up professional expertise. This categorization can be compared to Pawson et al. (2003) classification of knowledge into organizational knowledge (including regulation), practitioner knowledge (experience), user knowledge (cli- 
ent's situation), research knowledge and policy community knowledge (including ideological and political reasoning). While explicit standards can be found in both organizational and research knowledge, the other knowledge sources tend to lack this aspect. Payne (2007) applied Pawson et al. typology of knowledge in social work practice and found that different forms of knowledge were used in different phases of interaction. He concludes that knowledge is embodied in the practitioner, including theoretical knowledge, and that practice is always provisional.

In light of a historical presentation of Swedish child welfare services, Nordlander (2006) argues that investigation work does indeed draw on different knowledge sources and embrace client-professional relations, but also that it can be a powerful control tool, as it is the practitioners who decide on what should be assessed and which interventions are attainable. It is worth noting that less than half of the applications and reports that come to the attention of child welfare services actually lead to investigations (Östberg 2010).

\section{Learning in work}

Knowledge of contexts is often thought to be acquired through an implicit or informal process of socialization through observation, introduction and participation (e.g. Pawson et al. 2003). If such a process remains unexplored, White (1997) shows that the tacit knowledge becomes impossible to challenge and risks nurturing prejudice, personal beliefs and behavior. According to Van de Luitgaarden (2009), social work practice generally relies on intuition rather than on analytical reasoning, which makes the articulation of tacit knowledge difficult and moreover constrains learning.

The culture in social work tends to emphasize learning through practice (Sheppard et al. 2000). Indeed, there is a strong tradition of authority-based practice in social work. The transfer of professional knowledge from a senior to a more junior colleague is considered an essential aspect of learning the craft of social work (Gambrill 1999; Gibbs \& Gambrill 2002; Sheppard 1995). Research shows that collegial control of work, together with the value of professional jurisdiction, is central to professional practices such as social work (e.g. Healy 2009; Munro 20II).

Munro (2010) finds that the new managerial preferences belonging to new public management are obstacles to the development of a learning process in social work practice. She argues that a top-down control system views improvements in work in terms of greater compliance with procedures and rules. This view of improvement, or indeed learning, aligns with the adaptive mode of learning described in Chapter 3. 
This mode of learning is important in developing skills for handling routine tasks or problems that occur in daily practices (Ellström 200I; 2006), but is argued to be insufficient in meeting the growing demands of social work practice (Munro 20II).

While compliance with and uniformity of procedures and rules are essential measures in a risk society, Broadhurst et al.'s (2010) study shows how informal processes continue to play a critical role in decision making and actions in practice. Also, Gillingham and Humphreys's (2010) study among social worker in an Australian setting shows that structured decision-making tools are not being used as intended and that the "mis-use" in fact undermines the development of expertise. The fact that decisions often were being made some time before the tools were either applied or completed suggest that the tools are organization-focused and not user-focused, thus mainly used as a device for accountability. Many researchers (e.g. Baldwin 2004; Broadhurst et al. 2010; Munro 2010) claim that a greater understanding of the impact of informal processes in social work is necessary not only to promote adaptive learning processes, but also to support learning that offers changes in work practices (cf. developmental learning, Ellström 200r; 2006). To what extent the social workers in fact challenge their knowledge base by practicing critical reflection is something we know very little about (Nordlander 2006).

\section{Evidence-based practice meets social work}

As indicated in the introductory chapters, evidence-based practice has rapidly expanded from medicine and advanced into the field of social work (Morago 2006; Thyer 20I2). At face value, it is easily accepted across a range of disciplines in the social services, but difficulties arise when the specific steps associated with application of the model are introduced (Börjesson \& Johansson 20r4; Otto et al. 2009). The evidence-based model is largely theory-neutral and conceptual (Thyer 2012) and has not been implemented as something uniform, which opens the door to individual interpretations (Bohlin \& Sager 20II; Gambrill 2007; Gray et al. 20I4).

Various studies have shown that investigation work has become simultaneously more monotonous and more complex (Gambrill 20I2; Lindquist 20I2). These two seemingly contradictory developments are highly interactive. The monotonous part of work has developed, at least partially, through the growing number of tools used for standardizing work processes and the increasing specialization in departments and functions. In turn, the complexity of investigation work has developed through increasing requirements for widespread co-operation with other actors in the local 
area and the greater extent of medicalization involved in the cases. Furthermore, successful development of a critical appraisal model of evidence-based practice is complicated by the fact that the social workers conducting investigations in child welfare tend to be newly recruited (Lindquist 20I2). Recent statistics show that one in three social workers in Sweden has worked fewer than three years (Socialstyrelsen 20I4, p. 25). The high personnel turnover and lack of resources obstruct possibilities to maintain and develop professional knowledge and practice (Socialstyrelsen 2015).

Broadhurst et al. (2010) find that the development of a variety of instruments in social work reflects an ideological commitment to scientific and instrumental rationalism, which they believe reduces decision-making options and minimizes inclination (feelings). With the aim of improving what they call "unassisted" professional judgment by regulating and structuring the decision-making process (workflow), the authors observe a risk that judgments will be made on weak grounds, leaving "the informal logics of risk that are so central to professional practice under-emphasized and under-theorized" (p. I05I). Rosen (2003), one of the prominent advocates of the rational decision-making model, on the contrary, finds that an emphasized structure (or guided practice) can support practitioners in the often complex situations they encounter.

The literature suggests that there are several differences between the developments of evidence-based practice within social work in the US and Sweden. This was briefly mentioned in the introductory chapters and is somewhat elaborated on here. First, the US Government is decentralized and favors a market-related development of professions, in comparison to Swedish professionalism, which traditionally has been more closely connected to the growth of the state and to state bureaucracies (Svensson \& Evetts 20Io). Second, the Swedish evidence-based movement into social work started as a state initiative in contrast to the strong professional influence in the US (Bergmark et al. 20Ir; Börjeson \& Johansson 2014). Third, pluralism and competition are characteristic of the US, which has allowed multiple organizations to develop different support tools to promote transparent and evidence-based practices. This has not been the case in Sweden, where practitioners put great trust in the state to develop useful tools for more evidence-based practice. Also, it should be mentioned that social work in Sweden is carried out from a perspective of support, undertaken without any specific diagnosis or models of intervention, contrary to some other countries in the West that to a greater extent exercise control based on various intervention models (Bergmark et al. 20II; Bergmark \& Lundström 2002). 
To a great extent, evidence-based practice in Swedish social work has become synonymous with using specific evidence-based practices (methods, interventions, programs, etc.) (Soydan, 20Io). Evidence-based practice in terms of individual social workers' critical appraisal and decision-making processes has met with modest acceptance (Bergmark et al., 20I2; Gray et al. 20I4). A survey by Sundell et al. (2008) within the individual and family services in Sweden indicated that more than sixty percent of the services used "evidence-based methods." However, many of these methods, e.g. assessment instruments, documentation systems and interventions, had limited empirical support. Bergmark et al. (2012, p. 602) claim that these methods bear little resemblance to any kind of standard applicable for evidence-based methods, arguing that the findings could be attributed to respondents' social desirability and wanting to "do the right thing" in the eyes of the national agency and other stakeholders.

Ultimately, it is something of a paradox that empirical research support for the beneficial effects of applying evidence-based practice is fairly limited within social work (Bergmark et al. 20II). There is no obvious "evidence" of evidence-based practice being used in practice or that applied evidence-based practice actually improves client outcomes (Thyer 2006). 


\section{Aim and research questions}

AgAinst THE BACKDROP of the transformations in the entire framing of professional work, social work has come under close scrutiny in many countries, including Sweden. Doubts have been raised about practitioners' existing knowledge base, and the importance of practitioners engaging in learning and the renewal and extension of professional capacities has been emphasized.

The aim of the present thesis is to explore processes of knowledge use and learning in practice. Four research questions were addressed:

I. How can workplace reflection provide a mechanism to integrate research-based knowledge with pre-existing practice-based knowledge?

2. How is the notion of evidence-based practice understood among politicians, managers and executive staff within social work?

3. How can processes of knowledge use in everyday practice be described and understood?

4. How can social workers' learning and sense making in daily practices be described and understood?

These questions correspond to the research questions that were addressed in the appended four articles. Article I presents a theoretical framework for improved understanding of how workplace reflection can be used to integrate different knowledge forms to achieve learning. Article II identifies a number of different understandings of evidence-based practice among actors in social work. The article describes what people talk about and how they talk about evidence-based practice in terms of practice, knowledge and quality. Article in identifies what knowledge sources are used in social work practice that involves investigation work, in what ways and for what purposes. Article IV analyzes the basis of practice and identifies a variety of learning opportunities in everyday child investigation work. 


\section{Methods}

THIS CHAPTER DESCRIBEs the research setting and research process, including the methodological approaches that were used in the four studies comprising the thesis. The chapter also elaborates on ethical considerations concerning the research project, the quality of the study and the role of the researcher.

\section{Research setting}

\section{Child welfare services in Sweden}

Social work is part of the Swedish welfare model, which is divided into three levels: state, county councils and municipalities. The political power is decentralized and the 290 municipalities have extensive autonomy. Each municipality has an elected council that has powers over most matters of local administration and acts as a frontline agency in social care delivery (Soydan 20Io).

Sweden has a long tradition of nurturing a well-developed welfare state (Soydan 20Io). Municipal social care services (“Socialtjänsten”) employ approximately 250,000 people, including social workers, nurses, nurse aids and eldercare nursing staff (SKL 20I2). In most municipalities, social care services are organized in specialized functions, which often are categorized according to the client's age or problem (Bergmark \& Lundström 2005). It is also common for different divisions to be responsible for different case-related tasks, such as a receiving department that decides whether or not an investigation should be opened, an investigation department that assesses the client's needs and a department (internal or external) that supplies and follows up on the chosen interventions. With regard to the organization of child welfare, it is for the most part divided into separate departments that investigate and serve clients' needs (Lindquist 2012).

The primary law governing social care in Sweden is a goal-oriented enabling act based on voluntary efforts (Social Services Act). Up until 20I4, the Social Services Act lacked specified knowledge standards for child welfare. Today, it is regulated 
by law that work must be conducted by professionals with a Swedish degree in social work or equivalent (Socialdepartementet 2013). The union for professionals also provides ethical guidelines for work in the social services sector: "Professional social work is based on science and professional expertise, democratic and humanistic values, and helps to realize human rights and the development of social welfare" (sSR I997, p. 7).

The legal framework allows professionals considerable autonomy in combination with extensive trust. The often complex matters handled in social care require cooperation with many local actors, such as the schools, police, psychologists, healthcare and migration (Lindqvist 20I2). Work is primarily carried out in a spirit of consensus with the client, and only in rare cases does the legislation call for coercion (ibid.; Rasmusson et al. 20I0).

\section{A focus on investigation work}

The present study focuses on practices of child investigation work, and thus a brief description of structural aspects is provided. In 2006, the National Board of Health and Welfare decided to introduce a new documentation system called Children's Needs in Focus (BBIC) ${ }^{\circ}$ followed by an attached license requirement (Socialstyrelsen 2006). Most social welfare agencies, including the participating agencies, have adapted to the use of a web-based version of BвIC for investigating, planning and evaluating the work with individual children. BBIC identifies the three types of information (illustrated with a triangle) the social worker needs to gather in the investigation process: information about the child's needs, the parents' ability to provide for these needs and other circumstances that might affect the child's development. BBIC adheres to the British Integrated Children's System, which is viewed as a standardized approach to conducting an assessment of a child's additional needs and has had a significant influence on how child investigation work is organized in more than fifteen countries (Rasmusson et al. 2010).

A child investigation is based on knowledge about the apparent risk for the child, either through an application from the family themselves or a report from someone outside the family. The legislation requires that the case be handled quickly and completed within four months of being opened. The social workers are responsible for conducting the investigations. Based on the recommendations made by the

6. Today, 284 of Sweden's 290 municipalities use BBIC. BBIC has been adjusted twice since its introduction in 2006. In the autumn of 2015, yet another new version will be implemented, together with a national educational program (Socialstyrelsen 2015). 
social worker in charge, the elected local council, operated by local politicians, decides on future actions. The interventions are thereafter usually executed by others, often by less educated staff (Tengvald 2008).

A final comment on the broader setting in which this research project takes place is needed before I move on to describing the local setting. During this project, there has been a consistent and lively public debate concerning the situation in Swedish child welfare services. Investigation work has been portrayed in the media as an organization under high pressure. Studies have reported on a high personnel turnover and difficulties in recruiting qualified staff, the consequence being that many young women, with limited work experience, are responsible for handling difficult cases and making decisions in matters that may have severe effects for children and their families (Lindquist 20I2; Socialstyrelsen 2015; sou 2009:68). Most of the social workers resign within two to three years, which reduces possibilities to retain and develop the knowledge base in the organization (Socialstyrelsen 20I5). The situation has been shown to result in resources being used for recruiting and introducing new personnel instead of for focusing on dealing with issues of competence and quality improvements (Lindquist 20I2).

\section{The local research setting}

The present research project was initiated as part of a research and development $(\mathrm{R} \& \mathrm{D})$ project entitled Families in social care services, which was carried out by the Research and Development Center for Healthcare and Social Work in the Municipality of Linköping in collaboration with six other municipalities in the region and with Linköping University. The R\&D project targeted children and families in socially and economically vulnerable situations and aimed at gaining a better understanding of their life situation and their experiences of the social welfare services. In contrast to this larger R\&D project, the research project presented here focused on the social workers and their professional practices, in particular, their investigation work.

Three of the municipalities that participated in the above mentioned R\&D project were invited to participate in this research project. One of the municipalities is a metropolitan area with a population of 150,000 , whereas the other two municipalities have a population of 42,000 and 25,000 , respectively.

Fifty-five social workers ( 52 women and 3 men) conducted investigation work in the three agencies and four managers supervised the work. Although not all social workers were participants in the present study, a brief description of the personnel is given. The social workers were between twenty-three and sixty-three years of age, 
the majority below forty. A few were newly recruited and others had worked in their present positions for close to thirty years. Many of the social workers also had work experience from other parts of the social services sector. All had a university degree, the majority in social work. The agencies shared many characteristics with other agencies throughout Sweden (including increased specialization and high personnel turnover). A more detailed specification of the participants is found in the following description of the research process.

\section{Methodological approaches}

It is challenging to study cases in a "naturalistic" societal setting, such as social work, especially when a research process is initiated exclusively from a researcher's point of view (Uggerhøj 20II, 20I2). Nowotny et al. (2003, p. I8I) argue that knowledge is highly reflexive and that research no longer can be characterized as an "objective" investigation of the natural or social world; instead research has become a dialogic process between the researchers and the research subjects.

Miles and Huberman (1994) described key features of qualitative research, which are applicable in the present study and somewhat elaborated in the following sections. They posit that qualitative research: (I) is conducted through intense contact with a "field" or life situation; (2) is carried out to gain a "holistic" overview of the context under study; (3) attempts to capture the perceptions of local actors "from the inside"; (4) allows for the researcher to select and isolate certain themes and expressions from the material that can be reviewed with the informants; 5 ) seeks to explicate the ways people in a specific setting come to understand, account for, take action on and manage their day-to-day situations; (6) allows many interpretations of the collected material; (7) uses little standardized instrumentation; (8) and analyzes data with words (pp. 5-7).

In the following sections I will give a more detailed description of the three methodological approaches.

\section{Conceptual case study}

The first approach used to address the research questions in the present thesis can be characterized as a conceptual case-study approach (Study I), that is, a theory-driven approach. Miles and Huberman (I994, p. I8) describe that a conceptual framework explains the main issues to be studied and the presumed relationships among 
them. Two mini-cases were used to illustrate practical implications of the developed framework.

\section{Phenomenography}

The second study (Study II) in the thesis used a phenomenographic approach to the design of data collection and data analysis. Phenomenography is defined as a methodology to reveal qualitatively different ways of understanding a phenomenon (Dahlgren 1998; Marton 198I). People's understanding of a phenomenon is thought to be found in a limited number of qualitatively different ways and from a phenomenographic point of view, the ambition is to reflect these understandings and not judge them as right or wrong (Marton \& Booth 2000).

If the aim is to better understand how people deal with problems or situations, phenomenography suggests taking the understanding of the problem or situation to be dealt with as the starting point. A common method to uncover people's understanding of a problem or situation (i.e. a phenomenon) is to conduct interviews. Ten to fifteen interview transcripts are recommended to be an ideal number to analyze at one time (Åkerlind 2005). To obtain a deep understanding of the respondent's ways of understanding the studied phenomenon (i.e. in the present study evidence-based practice), abstract and decontextualized questions can be combined with encouragements to describe the phenomenon through direct experiences and visualizing the consequences, referred to as "situated examples" (ibid., p. Io6).

\section{Ethnography}

Ethnographic fieldwork was carried out in two of the studies (Study III and IV) in the thesis. Ethnography enables an exploration of naturally occurring processes in situ (Agar 1996; Miles \& Huberman 1994). The researcher is located at the center of social worlds and is a participant in daily life (Agar 1996).

Participant observation constitutes the primary research method used in ethnography, with interview data often providing an important background for an analysis of the observed (Agar 1996). Being a participant observer calls for a reflexive awareness in social relations, which implies an active stance. Thus, the term observer is somewhat misleading.

Flyvbjerg (2006) argues that the study of real-life situations requires a closeness, which implies the context dependency of social science. This closeness is of twofold importance. First, it can offer the development of a nuanced view of reality and enable a meaningful understanding of human agency. Second, it can support the re- 
searcher's own learning process through concrete experiences and feedback from the participants in the study. From this point of view, ethnography can be viewed as an interactive approach, which is characterized by joint learning and opportunities for critical knowledge creation (Aagaard Nielsen \& Svensson 2006; Humphries 2003).

Ethnography can also be characterized as participation oriented (Humphries 2003, p. 87) and collaborative, whereby the researcher is dependent on a few key people to teach, work with and help him/her figure out what is going on in their world. These people may in fact be considered co-authors (Agar 1996). Participatory research emphasizes the attempts made by participants and researchers to collaborate as equals and influence each other, which enhances the validity or trustworthiness of the research findings (Humphries 2003).

Ethnography requires that the researcher is able to establish a close and trusting relation with the participants (Agar I996; Alvesson \& Sköldberg 2009; Miles \& Huberman 1994). The understanding of the people and entities in everyday contexts begins in local sites of activity (Hall \& White 2005).

\section{Research process}

The research process was divided into four phases: (I) planning, (2) data collection, (3) data analysis, and (4) feedback of results. The different research activities that were carried out during each of these four phases are summarized in Table 2.

The planning phase involved setting up formal prerequisites for conducting fieldwork that is ethically sensitive, such as doing research into settings that involve clients. An in-depth discussion on ethical issues follows in a separate section of this chapter. The planning phase also involved activities to attain more practical access to the field. The manager and steering committee ${ }^{7}$ for the above-mentioned R\&D project served as an important link to practice. At a first meeting with the committee, I presented my research interest and reviewed the municipalities' interest in participating. Following the meeting, the project manager, my supervisors and I made a joint decision to follow up on three of the municipalities. The municipalities were chosen on the criteria that they were of different sizes and were believed to capture the variation present in a normal county area. Next, I met with managers in these

7. The steering committee engaged managers and social workers from the seven municipalities that were involved in the R\&D project. 
municipalities' child welfare services to learn more about their organizations and what they deemed were interesting issues to focus on in my study.

After finalizing Study II and preparing for the fieldwork, I once again turned to the municipalities. At this point, I met with line managers to establish a shared understanding of my research plan. We decided that I should proceed with the fieldwork into two of the municipalities to address my research questions. Before the fieldwork began, information was sent to the managers to be distributed among all staff.

Table 2. Overview of research activities linked to the separate studies

\begin{tabular}{|c|c|c|c|c|}
\hline Phase & Activity & Study & Study & $\begin{array}{l}\text { Study } \\
\text { III-IV }\end{array}$ \\
\hline \multirow[t]{5}{*}{ Planning } & $\begin{array}{l}\text { Applications to the regional ethical vetting board } \\
\text { and local authorities }\end{array}$ & & & $x$ \\
\hline & Two pilot interviews & & $x$ & \\
\hline & Distribution of research information to the field & & $\mathrm{X}$ & $x$ \\
\hline & Meetings with steering committee and managers & & $x$ & $x$ \\
\hline & $\begin{array}{l}\text { Correspondence such as e-mail and phone calls } \\
\text { concerning various issues }\end{array}$ & & $x$ & $x$ \\
\hline \multirow{7}{*}{$\begin{array}{l}\text { Data } \\
\text { collection }\end{array}$} & Step 1. Reanalysis of previous case-studies & $x$ & & \\
\hline & Step 2. 14 individual interviews & & $x$ & \\
\hline & Step 3. 3 individual interviews & & & $x$ \\
\hline & 21 occasions of participatory observations & & & $x$ \\
\hline & 17 reflective dialogues & & & $x$ \\
\hline & 2 focus groups, including 21 questionnaires & & & $x$ \\
\hline & 5 case documents, including journal notes & & & $x$ \\
\hline \multirow{3}{*}{$\begin{array}{l}\text { Data } \\
\text { analysis }\end{array}$} & Theory-driven & $x$ & & \\
\hline & Phenomenographic & & $x$ & \\
\hline & Ethnographic & & & $x$ \\
\hline \multirow[t]{5}{*}{$\begin{array}{l}\text { Feedback } \\
\text { of results }\end{array}$} & $\begin{array}{l}\text { Reporting to the steering committee } \\
\text { and managers }\end{array}$ & & $x$ & $x$ \\
\hline & $\begin{array}{l}\text { Presentation of findings at different conferences, } \\
\text { work-shops and seminars }\end{array}$ & $x$ & $x$ & $x$ \\
\hline & Education and training & $x$ & $\mathrm{x}$ & $x$ \\
\hline & Article writing & $x$ & $x$ & $x$ \\
\hline & Writing of book chapters & $X$ & $x$ & $x$ \\
\hline
\end{tabular}


The data collection phase consisted of three separate steps: (I) Data were obtained through a theory-driven reanalysis of two case studies that had been carried out as part of another project; (2) data were collected through an interview study with politicians, managers and executive staff in the three participating municipalities; and (3) data were obtained from the ethnographic study that had been carried out in two municipalities.

The first data collection phase was conducted during the first part of $201 \mathrm{I}$ and thus began somewhat parallel to the planning phase. Two empirical cases on the utilization of research-based knowledge in reflection for managers in the Swedish public sector were re-analyzed and provided data for the study. A review of the literature on reflection and workplace learning was conducted to build a conceptual framework.

The second data collection phase took place during the autumn of 2011 and consisted of fourteen interviews with people ( 6 women and 8 men) from three levels in the participating three municipalities: political, managerial and executive staff. The respondents were chosen on the basis of the positions they held as important stakeholders and decision makers in the chosen municipalities with regard to service delivery in social work. The interviewees who belonged to the managerial (6 persons) and staff ( 3 persons) levels had an average of twenty-five years of working experience in the social service sector, ranging from one to thirty-nine years; the politicians ( 5 persons) had served an average of twelve years. The length of time in present positions varied from one to twelve years; staff had served the greatest number of years and politicians the least. The respondents were between thirty-five and sixty-one years of age. All managers and staff had a university degree, whereas none of the politicians did.

An interview guide was used, which had been piloted with two social workers, but was not included in the study. All interviews began with the question "What is evidence-based practice?" The initial question was followed by encouragements to describe the phenomenon through direct experiences, its merits and the principles comprising it. To verify that the respondents' descriptions were interpreted correctly, statements were summarized during the interviewing. Each interview took approximately forty-five to sixty minutes.

The third data collection phase took place between August 2012 and May 2013. The fieldwork began with focus group interviews. A short questionnaire was distributed among the participants to collect relevant background information. Thereafter, four social workers were selected in dialogue with the managers, contacted indi- 
vidually and asked to participate in the study. One criterion for selection was that the participants should have completed their introductory year. This open strategy was deemed important to getting the whole workplace to agree to my presence as a participant observer during daily work in the unit.

Including team partners, seven social workers were engaged in the study. All were women with a mean age of thirty-five. They had worked for an average of two and a half years in their present position, but three had work experience from other branches of the social services.

Five cases were selected in cooperation with the practitioners and reviewed from the opening date until decisions were made and the cases were closed. I thus took part systematically in all types of activities related to these cases.

The main method used in gathering data was field notes from participant observations. The encounters in the field produced a large number of notes that were initially written down in notepads. Besides field notes, the data consisted of taperecorded reflective dialogues, interviews with managers and recordings from reading the case documentary.

The analysis phase comprised four phases linked to the four studies in the thesis. The studies used somewhat different analytical strategies. However, all data used in the present study were in the form of words, which in turn were based on observations, interviews and documents. Also, the analysis was done with words (Miles \& Huberman 1994).

The analysis in Study I was built on theory and data from a review of previous research and theories on learning and knowledge use and illustrated by empirical findings from three case studies that had been carried out in a previous project.

In Study II, semi-structured interviews served as the basis for the analysis. All interviews were in Swedish, and were tape recorded and later transcribed verbatim by an authorized transcriber. A phenomenographic analysis procedure was performed in accordance with the seven steps described by Dahlgren and Fallsberg (I99I):

STEP I. Familiarization, I read through the data;

STEP 2. Consolidation, I marked and recorded interesting passages in a table; 
STEP 3. Comparison, I re-read the accounts in search of similarities and differences allowing different aspects of the phenomenon to emerge;

STEP 4. Grouping, I searched for a pattern that could illustrate the data excerpts collected;

STEP 5. Articulation, I focused on how the aspects delimited in Step 3 were perceived and related internally in order to develop descriptive categories;

STEP 6. Labeling, a name was given to each denoted category;

STEP 7. Contrasting, an investigating of internal relationships across the categories was done to reveal possible hierarchical relations between them.

All the materials used for analysis in Study III and Study IV emerged from the fieldwork. However, the data that were represented by the raw field notes or tape recordings required some processing before it actually could be analyzed. The coding of data entailed deliberation over words, sentences and paragraphs that were relevant to the research questions and, as indicated by Miles and Huberman (1994), meant an iterative process of three parallel flows of activity: data reduction, which involves a process of selecting, simplifying and transforming written field notes or transcriptions; data display, which concerns organizing the data; and drawing conclusions.

I transcribed all recorded data and raw field notes myself, which provided an opportunity to re-visit situations and reflect on emerging issues during the research process (Miles \& Huberman, 1994). In Agar's (1996) terms, this can be described as an analysis that takes place at a distance (back-stage). However, as Agar explains, it is equally important to analyze the data in practice (on-stage). This was made possible by involving the participants in reflective dialogues during the preliminary analysis and interpretation of the data. Conducting reflective dialogues was also a way of validating the data and providing an opportunity for joint learning during the analysis (Aagaard Nielsen \& Svensson 2006; Humphries 2003). In Miles and Huberman's (I994, p. 275) terms, this activity can be seen as a "feedback" activity in which the informants function as sources of confirmation.

While the analysis in Study III drew on the full amount of data collected in the field, to address the aim of Study Iv, one ordinary day of work was extracted from the extensive data and formed the basis of the analysis. The events that took place on 
this day were extracted for the analysis. Events are part of a process and of interest as they help to build a narrative (Miles \& Huberman I994). The events may also characterize learning in action routines. Weick and Westley (1996, p. 449) suggest that by viewing 'learning as a moment in a process,' attention can be drawn to learning just as it appears in the normal work processes of daily practice.

The feedback phase concerned the activities of dissemination of results linked to the research project. While Table I presents this phase at the end, most of the feedback activities actually took place during the research process. From this point of view, the feedback phase can be characterized as interactive and constructive for validating the research findings during the research process.

As yet, the findings from Study II and III have been reported to the steering committee of the R\&D project. The findings from all the studies have been discussed in a wider research community, both at a national and international level, such as at conferences and higher-level seminars at different universities. Furthermore, the findings have informed educational and training activities.

Lastly, the research findings have been validated and disseminated in articles and two book chapters are in print.

\section{Quality of the research project}

There has been a long-standing debate among researchers concerning the relevance of concepts such as reliability, validity and generalization in qualitative research. Tobin and Begley (2004) advocate a more pluralistic approach as a means of legitimizing naturalistic inquiry and discuss terms as "goodness," "dependability" and "trustworthiness." The critical point they make is that qualitative researchers should be explicit about their choices of legitimizing criteria.

The intention in this chapter, as well as in previous chapters, is to achieve transparency by carefully describing the research setting, questions and process, including methodological and analytical choices, to make it possible for other researchers to critically evaluate the findings. As Patton (2002) argues, how the quality and credibility of qualitative research is assessed will depend on the "philosophical underpinnings and theoretical orientations" of the researcher (p. 266), but also on the researcher's ability to carefully describe the research process. Ultimately, the authority to judge the quality of the study is given to the readers. 
Reliability concerns the quality of being exact, careful and strict in processing and structuring a study (i.e. internal logic) (Miles \& Huberman I994). In Tobin and Begley's (2004) terms, reliability is comparable with dependability, which they believe can be demonstrated by an "audit trail" (p. 392), allowing others to audit and examine the data, methods, decisions and end product. A relevant question regarding reliability is whether consistency is created between the research questions, data collection and in the end analysis and conclusion.

The four studies comprising the present study have undergone peer review and been accepted for publication in different international journals, suggesting that they are characterized by a certain scientific rigor.

Another aspect that might be relevant to judging the quality of a study is to assess its internal validity, that is, to review the strength and significance of the findings. Tobin and Begley (2004) use the concept of credibility as roughly equivalent to internal validity. Relevant questions might be: Do the findings of the study make sense? Are interpretations and conclusions reasonable given the data? Are alternative interpretations considered and, if possible, excluded?

A major challenge has been to make sense of the massive amounts of data that the study has generated. While my initial intention was to engage the participants in a joint learning and knowledge creation process, at this point, when writing down my experiences, I realize that my initial ambition could not be fulfilled. I took a more pragmatic or utilitarian approach (Miles \& Huberman 1994; Patton 2002). Patton describes the utilitarian stance as involving a straightforward quality inquiry with a certain degree of situational responsiveness and methodological flexibility. In this case, in my attempt to make sense of the complexity that real-life research involves, I continuously needed to interpret the importance of different experiences and prioritize among various activities.

Although I might not have been as inter-subjective and interactive as intended, the assessment of findings was quite collaborative. Collaboration is for instance found in the reflective dialogues. Reflective dialogues with the social workers were carried out to examine observed actions and issues deemed important to the research project in the spirit of joint exploration, similar to what has been referred to as InterView (Kvale \& Brinkmann, 2009). Thus, as Miles and Huberman (I994) suggest, it was possible for me to select and more closely examine certain expressions and behaviors. The dialogues created a setting for me and the social workers to examine the data observed and engage in a dialogic process of learning to understand the underlying working mechanisms (Alvesson \& Sköldberg, 2009), which otherwise 
have a very strong tacit dimension and might be difficult to learn about (Eraut 2007). In this way, knowledge could develop from within the practical context rather than exclusively from externally observed engagements (Hall \& White 2005). It was also a way of validating the preliminary findings during the process.

Collaboration was furthermore involved in the follow-up questions and summaries that took place during the interviews, in analyzing the material together with my supervisors and other researchers andhow in the papers discussed at seminars and conferences within the broader scientific community. Thus, I assume that, in several respects, my thesis can be considered a collaborative undertaking, which can lend support to the internal validity (credibility) of the study. Also, the use of different social welfare service departments enabled the identification of patterns across practice settings, supporting stronger internal consistency.

Finally, some words concerning the question of to what extent the present findings can be generalized or transferred to other settings. In Tobin and Begley's (2004) terms, "transferability" is comparable with external validity or generalization. The possibility of generalizing the findings in a statistical sense is of course limited when only three social welfare agencies serve as the basis for data collection. On the other hand, Giddens (1984) argues that the social sciences should primarily provide conceptual schemes rather than explanations of a generalizing type. However, it may be possible to make some claims about analytical or theoretical generalization and generalization through context similarity (Larsson 2009).

First, Shaw (200I) stresses that it is context that provides meaning, in terms of the research being practically useful. With regard to the present study, if I am interpreting Shaw correctly, if descriptions and findings are to be deemed transferable, managers and social workers need to be able to recognize themselves in them. Larsson (2009), with the support of Geertz, suggests that the interpretational world (e.g. a similar culture) is also required for research to be practically useful. Indeed, "it is the audience that is often in the best position to judge the similarity of context with the one portrayed in the research work" (p. 32).

The findings of the present study have been tested and verified in different settings, such as academic and professional communities ${ }^{8}$. Reviewers have thus both been professionals and academics, which suggest that similar findings would likely be found in other social work settings, at least in a Swedish social work context.

8. Examples of settings in which the findings have been valued can be found in the Feedback phase of the research process. 
The second view on generalizing concerns the possibility to compare the findings with previous research findings, a so-called analytical replication. The theoretical framework in the present study takes a broad perspective on professional work and professional learning, suggesting that similarities could be found, and actually have been found, in other occupational settings beyond the immediate study. Also, the fact that the present study uses different data sources as well as different methods (although all are considered qualitative methods) is supposed to support the findings (Miles \& Huberman 1994; Tobin \& Begley 2004). To confirm a finding by showing that it agrees with an independent measure of the same phenomenon is known as triangulation. Here, the use of multiple sources, such as case documentation, observation and interviews helped me double-check findings and was somewhat naturally built into the data collection. Triangulation was also, as Tobin and Begley (2004) suggest, a way to enlarge my inquiry by portraying the findings on the basis of various data sources, thus, "offering a deeper and more comprehensive picture" (p. 393).

In all, the conclusions drawn from the present study are unlikely to be limited to considerations of social work practice, because many of the present findings support previous findings from other settings of professional work and professional learning, which supports the study's external validity.

\section{On research ethics}

This study was granted ethical approval by two legal authorities. First, ethical approval was obtained from one of Sweden's six independent regional ethical vetting boards (reg. no. 20I2/292-31). Second, permission to use the case files for review was given by the participating municipalities (reg. no. SN 20I2-I69; 20I2/SN OIIO). Moreover, verbal consent was obtained from the social workers as well as from the clients involved in the different cases, and assurances of confidentiality were given. Informed consent is important to protect participants from being exploited, but also to legitimize the research (Ferdinand et al. 2007).

The analysis of findings has been conducted on a group-level and across the participating municipalities, which minimizes the risk of recognition on an individual level. The different cases are used as background variables and have only been used in general terms. To achieve the study aim, there has been no need to report details such as gender, ethnicity or family constellations. 


\section{My role as a researcher}

Being "ethical" in research, as argued by Ferdinand et al. (2007, p. 52I), is problematic if it is synonymous with remaining passive and objective in all situations. Participant observation is engaging (Agar 1996). There is no real separation between subject and object, which creates difficulties in keeping a sound distance to the research object, or research subject, which tends to be a more appropriate term (e.g. Nowotny et al. 2003).

Throughout the research process, I have to different degrees reflected on my role as a researcher. Occasionally situations have required a high degree of selfreflexivity, as others have been more accessible. It is difficult to acknowledge ethical dilemmas before actually being in the practice setting, instead, real ethical dilemmas had to be addressed along the way. In that sense, the ethical approval obtained for the study was of little assistance.

It was certainly easy to get carried away in the intense situations of child welfare work. During the research process, I found it increasingly difficult to assume the role of a neutral observer and the practitioners occasionally sought my opinion. I especially remember a situation connected to a police interrogation. The social worker and I were walking back to the office when she asked me for my interpretation of the interrogation. I was deeply moved by the situation that the child had been placed in and did not know how to respond. I was speechless, because I was afraid that if I opened my mouth I would not be able to hide my strong feelings. She looked at me and uttered something like: "That's right, I cannot ask you because you're not supposed to engage in discussions of what's right or wrong." Still, back at the office, she again turned to me, and asked for my opinion in the case. At that point, it felt unfair not to share my thoughts on the matter. Indeed, "if the ethnographer is to take the 'subjects' (and their subjectivity) seriously and engages in interacting with them, he or she becomes engaged in dynamic relations with them" (Hasu 2005, p. IIo).

The above example was one of many experiences that I shared with the social workers. In line with Hasu's (2005) suggestion, I truly believe that my subjectivity served as a resource in building a trustworthy case. It was first when I was detached from practice that I could change my stance and the observed became more neutral. I realized that the Dictaphone could be a useful device to untangle, or at least reflect on, the often ambiguous situations that needed my attention. On my way home from a day on the field, it became a habit to record my thoughts on the experienced encounters, which at that time served as a debriefing channel and later as an opportunity to return to the thoughts and questions that the experiences had triggered. 
A final comment on my role as a researcher concerns the importance of a mutual language. The use of an approved contextual language has been shown to fill an important role in qualitative research, especially with regard to ethnography (Agar I996). Before starting my doctoral project, I worked as a human resources developer in a fairly large social welfare department. Thus, I had a pre-understanding of the context in which social work takes place and with this an understanding of the institutionalized language. A natural consequence of my prior experiences was that I rapidly melted in and was seen as a part of the team by both the social workers themselves and the managers. In my case, I found that my ability as a researcher to address the practitioners and situations in the correct mode was an advantage, allowing me to quickly relate to the practitioners and build the trust needed to capture the perceptions of local actors "from the inside" (Alvesson \& Sköldberg 2009; Miles \& Huberman 1994). 


\section{Summaries of studies}

\section{Article I. Integrating Research-Based and Practice-Based Knowledge through Workplace Reflection.}

Nilsen, P., Nordström, G. and Ellström, P-E. (20II) Journal of Workplace Learning, $24(6), 403-415$.

Aim The study sought to present a theoretical framework aimed at improving our understanding of how reflection can provide a mechanism to integrate researchbased knowledge with practitioners' pre-existing practice-based knowledge.

Method The study was conceptual. First, a theoretical framework concerning characteristics of knowledge and workplace learning was offered. Second, two reflection programs conducted in the Swedish public sector provided mini-cases to illustrate how research-based knowledge can be used to challenge practitioners' practicebased knowledge.

Findings and contributions The findings showed that the programs had several characteristics that facilitated their implementation: They achieved a balance between the workplace demands on participating managers and the time required for reflection; the participants were specifically recruited, had full management support and were highly motivated to be part of the reflection groups; the facilitators played key roles in structuring the managers' discussions and linking their experiences to relevant research-based knowledge.

This study points to the relevance of certain organizational conditions that are of importance when organizing workplace reflection for practitioners and managers. 


\section{Article II. Ways of Understanding Evidence-Based Practice in Social Work: A Qualitative Study}

Avby, G., Nilsen, P. and Abrandt Dahlgren, M. (2013) British Journal of Social Work, 44(6), г366-г383.

Aim The aim of the study was to reveal how people working in social work view evidence-based practice. It focused on what they talked about and how they talked about evidence-based practice.

Method A phenomenographic approach to design and analysis was applied. From a phenomenographic point of view, the ambition is to reflect people's understanding of a specific phenomenon and not to judge a statement as right or wrong. Fourteen semi-structured interviews were conducted with politicians, managers and executive staff in three social welfare offices in Sweden.

Findings and contributions The analysis yielded five qualitatively different understandings of evidence-based practice in social work based on the relationship between three aspects: (I) how respondents believed evidence-based practice has influenced regular social work practice, (2) their perception of quality in social work practice in relation to evidence-based practice, and (3) their views on knowledge. The five understandings resulted in five main categories: (I) fragmented; (II) discursive; (III) instrumental; (IV) multifaceted; and (v) critical, which form an outcome space, hierarchically structured with an internal relationship so that understanding on one level encompasses understandings at lower levels.

The findings demonstrated that there was a broad range of understanding of evidence-based practice in social work. Furthermore, the findings suggested the informants' difficulties in accounting for evidence-based practice depend on what was expressed as deficient knowledge of the phenomenon in the organization as well as the organization's ability to provide a suitable context for evidence-based practice.

The contribution of this study is that it revealed multiple understandings of the concept of evidence-based practice in social work and the importance of acknowledging different facets of the concept when organizing a supportive atmosphere for evidence-based practice. It is suggested that the categories could be used as stimuli for reflection in social work practice, and thereby provide possibilities to promote knowledge use and learning in the evolving area of evidence-based social work. 


\section{Article III. Knowledge Use and Learning in Everyday Social Work Practice: A study in Child Investigation Work.}

Avby, G., Nilsen, P. and Ellström, P-E. (2015) Child E Family Social Work. Epub ahead of print 2015/03/12

Aim The aim of the study was to explore knowledge use and learning among social workers in everyday child investigation work.

Method The study was based on a mixture of qualitative approaches from ethnography to enable an exploration of naturally occurring processes in situ. Research was undertaken in two Swedish children's services departments. Methods included interviews, participant observations of formal meetings (staff meetings, client meetings, home visits and police interrogations) and other less formal meetings (collegial talks and everyday institutional tasks), reflective dialogues with social workers and documentary analysis of individual case records. Seven social workers were engaged in the study and five child investigations were reviewed from the opening date until decisions were made and the cases were closed.

Findings and contributions The analysis yielded a listing of knowledge sources that the social workers made use of in practice. The sources were positioned along a continuum according to the extent that the knowledge was tacit or codified. The knowledge sources were categorized as research-based, practice-based and ordinary knowledge.

The findings suggested that the relative importance of the knowledge forms differed between different phases of the investigative process. The social workers had a tendency to use practice-based knowledge, which was primarily conveyed from colleagues and previous experience; they showed less interest in knowledge from sources found outside the practice setting, such as research. Furthermore, the findings suggested that integration of various forms of knowledge was made possible through the social workers' engagement in a both verbal and tacit reasoning activity. In these processes of reasoning, knowledge was accumulated, disseminated, clarified, reflected upon and justified, which fostered learning at work. Finally, the social workers' learning could be distinguished as adaptive learning, as they learned to handle tasks in a fairly routinized way on the basis of a rule or procedure that drew on the existing knowledge base. 
The study contributes to social work practice by acknowledging the sources of knowledge that have traditionally been respected within the social work profession, yet whose validity continues to be contested. The study lends support to the notion that more evidence-based social work can offer potential learning benefits if the work can be organized to support easier access to, and use of, research-based knowledge in on-going practices. Thus, use of different knowledge forms has the potential to trigger learning and quality improvements in investigation work.

\section{Article IV. Professional Practice as Processes of Muddling Through: A Study of Learning and Sense Making in Social Work.} Avby, G. (2015) Vocations and Learning: Studies in Vocational and Professional Education, 8(I), 95-II3.

Aim The aim of the fourth study was to explore how social workers learn and make sense of experiences in their daily practices.

Method To address the aim of this study, one ordinary day of child investigation work was extracted from a larger ethnographic study. Five events that took place on this ordinary day were described and served as the basis for the analysis.

Findings and contributions The analysis portrayed a sample of activities in investigation work that were suggested to offer learning opportunities. However, the findings showed that the activities were not organized as learning activities; they solely exemplified everyday practice. Nevertheless, a certain degree of interplay between implicit and explicit knowledge was observed.

The findings indicated that interaction between different actors in work was a strategy used to enhance the level of knowledge and contribute to learning among professionals.

Overall, the study provides insights into the much-discussed topic of putting knowledge into practice. The findings lend support to a contextual rationality, which means that practitioners need to make judgments in a way that is sensitive to and relevant for their own contextualized settings. Contextual rationality is suggested to be a reasonable strategy for dealing with complex problems in daily practices that cannot be completely analyzed or solved. 
The contribution of the study is twofold: It offers an anlalysis of the basis of practice, which many practitioners have difficulty recognizing and articulating, and which unnoticed might create ambiguity in service delivery, and it identifies and portrays a variety of learning opportunities in everyday practice that could potentially be used in efforts to organize a more reflective practice and thus to facilitate improved workplace learning. These contributions are unlikely to be limited to considerations of social work practice. 


\section{Discussion}

The Aim of The PResent Thesis was to explore processes of knowledge use and learning in social work practice. Swedish child welfare services were in focus, more specifically the practices of child investigation work.

In this final chapter my intention is to discuss the knowledge contributions of the study by placing its findings in a broader context. I begin by summarizing the main findings of the four studies comprising the thesis. Based on these findings, it is possible to identify two central themes that I examine more closely. Thereafter, I present an outline of an emergent model of evidence-based practice, my aim being to describe the relations between the key concepts used in the study. Finally, I consider some methodological strengths and weaknesses of the study as well as implications for future research and for practice.

\section{Main research findings}

The main findings demonstrate that:

I. The meaning of evidence-based practice as experienced by actors in social work is far from a unified and coherent set of principles, suggesting that evidence-based practice is a far more complex phenomenon than what is usually described in the literature. It was possible to distinguish five different understandings of evidence-based practice among people working in social work, ranging from a fragmented to a critical understanding of the phenomenon (Study II);

2. Contrary to the ideals of evidence-based practice, investigation work was found to be characterized mainly by the use of practice-based knowledge. Use of research-based knowledge was limited in this practice setting (Study III, IV); 
3. Research-based knowledge was predominantly used as a means of explaining a client's situation or to underpin and legitimize one's own beliefs and decisions made on other grounds. Moreover, research tended to be reformulated and personalized before being applied in practice (Study III, IV);

4. Professional learning in and through work was found to be largely adaptive in character, as the social workers learned to handle tasks in a fairly routinized way on the basis of rules or procedures that drew on existing knowledge in the practice setting. Much learning tended to be embedded in daily activities, such as consulting colleagues, framing problems and building relationships (Study III, IV);

5. The social workers had a tendency to reason (e.g. argue, explain, rationalize) and make judgments in a way that was sensitive and relevant to their own contextualized settings, where norms, values and expectations provide explanatory frameworks. This form of reasoning, in accordance with a so-called contextual rationality, might be a reasonable strategy for dealing with complex problems in daily practices that cannot be completely analyzed or solved (Study IV);

6. Results from previous research together with two case studies carried out in a previous project (Study I) indicated that efforts to organize reflective activities at the workplace, such as reflective dialogues, reflection groups or debriefing in association with everyday activities, may provide a mechanism to integrate research-based and practicebased knowledge, offering potential benefits for professional learning.

Taken together, the findings of the fours studies showed that the social workers tended to, quite uncritically, draw on knowledge from colleagues and previous experience for immediate action and decision making rather than to engage in a broader search for knowledge and use of relevant knowledge.

Two conclusions (at least) can be drawn from the social workers' predominant use of practice-based knowledge. First, the use of knowledge in child investigation work bears little resemblance to principles of evidence-based practice, regardless of whether the evidence-based model is viewed as a rational decision-making model or a critical appraisal model. Second, the reproduction of professional knowledge is 
largely implicit and taken for granted, which limits the possibilities for a developmental learning mode and deliberate practice.

Now, given these findings, a number of questions emerge: Why does knowledge use among social workers look like this? Is this state of affairs acceptable and should it be left as it is? If not, what might be required to change or modify the prevailing situation? To what extent can evidence-based practice support both professional learning and an increased organizational effectiveness?

\section{Evidence-based practice - a legitimation of the status quo or a driving force for development?}

Although evidence-based practice has many qualities that may attract professionals in different fields to adopt it as a practice model, the study findings pointed to a number of obstacles and challenges that might muddle the development of evidence-based social work. As Dewey (1917) proclaims "a philosophy which exists largely as something to be taught rather than wholly as something to be reflected upon is conducive to discussion of views held by others rather than to immediate response." Taking Dewey's statement into account, it seems fair to say that social welfare services that uncritically adopt an evidence-based idea by addressing the evidence-based terminology to legitimize practice are taking a far too simplistic approach if the goal is to achieve the critical and developmental dimensions of evidence-based practice that were intended and advocated from the outset (e.g. Sacket et al. 1996). The same is true of organizations that implement evidence-based methods without considering the generalizability or applicability of the findings of the studies in which this evidence was established.

Bearing in mind that the idea of evidence-based practice calls for broad knowledge use, the complexity of work might increase. It would seem reasonable to ask how much "new" knowledge social work practice can endure and handle rather than suggesting what knowledge the practice needs. Knowledge does not always simplify life; it may also complicate it. Indeed, research-based knowledge is likely to lead to - implicitly or explicitly - a questioning of current practices.

On the other hand, implementation of and adherence to research-based methods and routines in social work practice might make it easier to articulate and realize well-defined goals. Application of validated methods might generate more standardized practices and reduce practice differences. As shown in the present study, the implementation of a new (compulsory) documentation system (i.e. BBIC) gener- 
ated improved transparency and structure in case reports. Still, the use of BBIC did not trigger a greater use of research-based knowledge. Another finding regarding the implementation of BBIC was that habitual writing practices seemed to be challenged and partially changed, suggesting that BвIC also created an opportunity for learning through reflecting on, criticizing and analyzing the data collected. As argued in Chapter 3, the codification of knowledge through a writing process is likely to increase the potential for learning from experience and may yield improvements in performance and knowledge integration.

The findings suggest that social workers applied knowledge in direct ways for action and decision making, implying instrumental knowledge use (Larsen I980: Weiss 1979). Importantly, however, the findings did not address instrumental research use. If social workers used research, it was mainly for legitimizing reasons, suggesting symbolic research use (Larsen I980; Weiss 1979). From a user perspective, research-based knowledge was often seen as divergent and oppositional, was easily rejected, and trust was placed in practice and personal experience. When deciding on what to do next, there tended to be little need to seek knowledge beyond what was provided in the intimate surroundings. Rather the findings suggest that social workers' knowledge use was highly situational and the reality often too complex to allow for a linear application of standardized methods. Many of the problems found in practice were not possible to completely analyze or solve, which compelled the practitioner to engage in a reasoning process in which meaning and order could rationalize their decisions (cf. practical reasoning, Molander \& Grimen 20Io). The direction of resoning depended on its use in the context of argument, thus, the social workers reasoning was both oriented forward, toward a goal, and backward supporting and justifying a conclusion that was known (Walton I990).

Eraut (2007) argues that many practitioners "survive," especially during their first years of employment, by reducing their cognitive load. One-sided evidence (i.e. knowledge) can have a profound effect on judgments, and people who are presented with one-sided evidence tend to be more confident of their judgments than those with multiple perspectives to consider (Kahneman 20II). Kahneman found that, in the decision-making process, people tend to have difficulty distinguishing between expertise and prejudice as well as a tendency to quickly jump to conclusions based on weak grounds, which indeed risks a practice based on more or less inaccurate and false ideas. "We often fail to allow for the possibility that evidence that should be critical to our judgment is missing - what we see is all there is. Furthermore, our 
associative system tends to settle on a coherent pattern of activation and suppresses doubt and ambiguity" (ibid., pp. 87).

In line with Kahneman's (20II) findings, Cohen and Lindblom (I979) argue that practitioners in many work settings tend to rely on the same ordinary techniques of reasoning that are practiced casually in everyday life. However, as exemplified above, reminders and vigilant monitoring can be useful in disrupting habits (Nilsen et al. 20I2).

\section{Learning as reproduction or development of professional knowledge?}

The study portrayed activities in investigation work that could have offered learning opportunities. However, the activities were not organized with a focus on promoting the social workers' learning. Overall, there tended to be little recognition of, or for that matter awareness of, how work could afford professional learning; rather work was focused on solving clients' problems and their often-complex situations. Fenwick (2003) finds that many practitioners indeed struggle to make sense of what counts as learning or learning goals, as these do not appear to be separate from everyday practice (also Billett 2004; Ellström 200I; Eraut 2004b). Also, the cultures that exist at a workplace may pose obstacles to professional learning (Fenwick 2003).

In the present study, a common understanding was that work was learned through observation, introduction and participation. As one of the social workers explained, "Work has to be worn in." Indeed, the reproduction of practice-based knowledge, largely derived from experience, was widespread. This finding is consistent with much of the previous research (e.g. Gambrill I999; Jensen et al. 20I2; Pawson et al. 2003; Sheppard et al. 2000). However, there is little to support the assumption that experience itself will expand professional expertise (Gambrill I999). Although the behavior of people may change as a result of experience, we know little of the validity of this knowledge due to the problems of justification.

Brehmer (I980) argues that we should be careful about basing activities on previous knowledge, regardless of whether the practices have been characterized as evidence-based or not, as the future is not certain and many times difficult to predict. Reliance on previous knowledge requires conditions to be stable and unvarying. The fact that "it works" says little about the truth of the knowledge (ibid.). This form of inductive judgment cannot be justified in the way deductive judgment can 
be justified. In other words, although the judgment may be true and serve as a basis for action, there is no way to confirm its truthfulness.

While informal procedures and logics indeed are central to professional practice, they tend to cause problems if they remain unnoticed and unarticulated (Broadhurst et al. 2oro). As argued in Chapter 3, if individuals' knowledge and skills remain tacit, there is a risk of underestimating the individual's competence and his/her contribution to the organization. There is also a risk that the development of tacit knowledge over time will lead to routines, as the individual starts to take shortcuts without considering that circumstances change, which evidently risks a loss of effectiveness (Eraut 2004b).

As shown in the first article (Study I), organized workplace reflection provided a means for deliberately promoting professional learning. In the reflection activities, practitioners deliberately drew on research-based knowledge to challenge existing practice-based knowledge regarding everyday situations and problems encountered in the workplace. The organized activities created a space for practitioners to articulate their often tacit, practice-based knowledge, thus triggering developmental learning. Study I points to the relevance of conceptual use of research, in contrast to the agenda of evidence-based practice, which emphasizes practitioners' instrumental use of research.

The finding from the study indicated that practice behaviors were quite stable and habits were easily formed. It is shown that if the cognitive system has a model developed through experience, which in addition has been proven to work, there is simply no need to find any better model to be used in a similar situation (Brehmer 1980; Lindblom \& Cohen 1979). Thus, neglecting negative information (i.e. contradictions to a belief or principle) makes sense under the so-called real world conditions in which people usually have to learn. However, this form of bounded-rationality (i.e. contextual rationality) and mindlessness is argued to create boarders to smartness (Alvesson and Spicer 20I2). Especially mindlessness points to how cognitive schemata enables routinized and effiecient behavior by its focus on cues and scripts, but, by doing so, largely ignores the broader concerns of lack of reflection or questioning (p. Irg8).

Thus, while the ability to develop cognitive schemata is a basic human instinct, it affects our ability to learn. Brehmer (1980) argues that we actually do not learn from experience largely because experience often gives us little information to learn from. However, Giddens (1984) argues that establishing routines and habits through learning from experience is one way to cope successfully with the daily flow of events 
while maintaining a sense of security and stability in life. In all, it is quite human to hold on to an intervention experienced to work, rather than seeking out new evidence of its ineffectiveness. But, over-reliance on experience and embedded habits may hinder the learning required to handle the increasing complexity and growing demands of social work practice.

\section{An emergent model of evidence-based practice}

In light of the preceding discussion, it is possible to outline an emergent model of evidence-based practice (Figure 2). Some of the concepts depicted in Figure 2 have been part of the research process from the beginning; others have developed over time. No matter in what way they have occured, I have gradually gained more insight into the concepts and how they might be applied in analyzing, validating and drawing conclusions based on the findings.

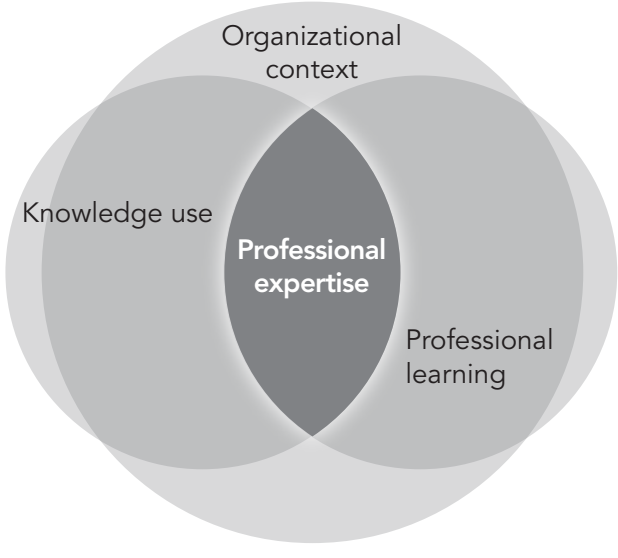

Figure 2. An emergent model of evidence-based practice as processes of knowledge use and learning

Professional expertise is the centralizing unit, as also found in established models of evidence-based practice. In comparison to the fairly simplistic evidence model commonly conceptualized in the literature, this model takes into account the complexity involved in developing evidence-based practice in practice. Importantly, the model adopts a broader view of the environment and organizational context (e.g. culture, norms, technical systems and regulations). Also, the notions of professional 
learning and knowledge use, take on more significance here. While evidence-based practice is considered to be allocated to the professional and take place in the clientprofessional relationship, it is the environment that enables and constrains the professional's knowledge use, and thus the opportunities for the individual to engage and be supported in his/her learning.

Essentially, professional expertise is the result of knowledge that is built up through conscious and unconscious processes of knowledge use and learning in work. Figure 2 implies the importance of organizing for professional learning and professionals' knowledge use in developing evidence-based practice.

A final point I wish to underline is the potential for developmental learning that exists in the instability or indeterminacy that may arise by interacting with different knowledge sources and questioning the taken-for-granted. In this sense, disorder, uncertainty or doubt is a positive force that is beneficial for learning and change.

\section{Methodological considerations}

As an ethnographic researcher, I entered social work practice curiously and openmindedly. However, as already indicated, some concepts, theories and indeed a certain pre-understanding were part of the research process from the start. According to Ferdinand et al. (2007) this is expected, as the kinds of stories that research tells are a mixture of the theoretical and conceptual questions that inform the research. Interpretation of any research requires a judgment to be made (Humphries 2003); and judgments are made by individuals and are not free form political, social, moral or ethical concerns and the views the researcher may have about the research carried out (Ferdinand et al. 2007). Also, it is assumed that it is impossible to conduct and write up ethnographic research without having a political impact upon the environment, as it brings about an enhanced awareness of the concerns of people going about their everyday activities (ibid.).

In Chapter 6 I have already discussed at a general level the strengths of conducting research in a participatory fashion. Here, I simply wish to emphasize some additional aspects with respect to the strengths and limitations of the study.

A major strength has been the fact that the initial interpretations of the data were analyzed and validated in reflective dialogues (i.e. respondent validation) (Aagaard Nielsen \& Svensson 2006), which enabled rapid correction of misunderstandings and reduced the risk of research bias (Eikeland 2006). Second, the joint discussions of what had been observed served as stimuli for workplace learning (Uggerhøj 20II). 
All participants acknowledged that discussing their work with me challenged them and increased their awareness of learning in and through work (can be compared to doubt or disturbance, in line with Pierce 1905). Third, reflective dialogues served as a fruitful way to understand the underlying working mechanisms (Alvesson \& Sköldberg 2009), which otherwise have a very strong tacit dimension and are difficult to learn about (Eraut 2007).

Furthermore, the present findings are largely validated through their congruence with results from previous research. For example, Nordlander's (2006) study on social worker's knowledge use in investigation work showed that social workers tended to apply an instrumental knowledge use for deciding on what interventions were appropriate. Also, Osmond's (200I) study revealed the extensive use of tacit, practice-based knowledge among Australian social workers.

Finally, I would like to say something about the risk of building trustworthy relations with participants - relations that are built into ethnographic research. Ferdinand et al. (2007, p. 533) question whether this closeness is not a form of deceit and exploitation. Sometimes I was concerned about whether the participants were too trusting toward me and treated me as one of their own. Occasionally I got carried away and I worried afterwards about how I might have influenced some situation. At other times I worried about the distance I created when refraining from engaging in discussions. As Agar (1996) states, there is no real separation between subject and object, which did indeed create difficulties in keeping a sound distance to the social workers and some situations I encountered during the fieldwork. From a validity perspective, there is of course also a risk of becoming too close to the participants in a study to be able to observe what happens from a sufficient distance. But as I already have argued, I developed the habit of using a Dictaphone to record my thoughts on my way home from a day in the field, which created a certain distance.

\section{Implications for practice and research}

Evidence-based social work has almost exclusively been debated from a theoretical and policy point of view. Existing studies concerning social workers' knowledge use are also often conducted "by detachment," that is, they are largely based on surveys of attitudes and opinions or interviews and have not been carried out in actual practice settings. Although there are exceptions (e.g. Ferguson 20I4; Nordlander 2006; Osmond 200I; White 1997; 2009), there is a paucity of studies on professionals' actual knowledge use. 
In line with this orientation, organizational efficiency programs, such as evidencebased practice, have often been carried out from a one-sided, top-down perspective (Bergmark et al. 2012; Börjeson \& Johansson 2014; Fenwick 2003), which might be counterproductive, as professionals value autonomy and self-regulation. Little attention tends to be given to work-related and other conditions at the local level (Estabrooks et al. 20I2; Lindquist 2012).

Considering the findings of the present study - not least the contextual constraints on the use of research-based knowledge in combination with a mainly routinized way of working and an adaptive mode of learning - one practical implication of these findings is the importance of organizing professional learning to meet the increasing demands on social work practice. According to Lindquist (20I2), this entails, among other things, training and development of employees and managers, support from first-line managers for employee learning in work, programs for mentorship, supervision and collegial learning.

One way of organizing professional learning and an increased awareness of existing knowledge structures at the workplace is exemplified in Study I. The study identified several characteristics associated with successful deliberate practice, such as supportive leadership, individual motivation, a well-designed project, training opportunities and feedback. The participants had full support from their respective managements and their participation was encouraged, which gave this activity some priority. The reflection activities were organized as reflection groups that met on a regular basis (e.g. once a month). Each reflection group was supervised by a facilitator whose task was to observe, provide a structure for the meetings and actively contribute to the discussions with theoretically based knowledge and experience in the areas of leadership and organizational development. The facilitator used challenging questions to make the participants examine their assumptions or opinions and discuss alternative ways of viewing the issues.

As argued by White (I997), the status of lay accounts tends to be marginalized or even ignored in evaluative studies of social work practice. Using this type of reflection activities might be a method to develop a knowledge base in and through work, that is, knowledge creation through practice-based learning. Whether or not this would work out in practice cannot be determined here, but could be an interesting issue for future research. Such a research task could use as its inspiration and theoretical points of departure theory and research on the concept of deliberate practice (e.g. Ericsson et al. I993), with its focus on creating space for experimenting with and evaluating practice-based interventions, but also the concept of knowledgeable 
practice, with its focus on learning in work through observation of others (possibly even "others" outside the practice setting), peer learning, mentorship and coaching (Evans in print). As Estabrooks et al. (20I2) argue, variables in the organizational context (e.g. leadership, feedback process, resources, including time, space, staffing and informal and formal interaction) are modifiable and therefore could be the focus of work environment interventions designed to increase knowledge interaction and knowledge awareness.

Considering the above and other possible interventions, it is also necessary to take into account the working conditions of the social workers in a broader societal perspective, including the conditions for professional social work. As discussed in Chapter 2, professionals in this and other professional fields tend to be closer linked to their work organization than before (Evetts 20I0; Svensson 2010). Such a gradual movement from an occupational professionalism toward an organizational professionalsm, and a corresponding increase in organizational requirements (e.g. performance measures) might have consequences in terms of a decrease in professional autonomy, which, as we know from previous research, is one of several important conditions for developmental learning in a work situation.

I would like to conclude with a hope for future practice and research on evidence-based practice: Instead of debating the pros and cons of different evidencebased approaches, it would seem to be more constructive for social work to foster critical thinking and communicative reasoning based on an encounter between research-based and practice-based knowledge. My hope is that the present study will make a contribution to the debate surrounding evidence-based practice in social work, possibly also to other professional fields, and indeed to strategies for organizing professional learning and knowledgeable practice. 


\section{Acknowledgements}

The TIME HAS COME TO PUT AN END to what started five years ago. Looking back, it truly has been an intense period in my life. This intensity has not been restricted to working life or my doctoral studies rather these amazing years have been life changing in more ways than I could have imagined. I feel fortunate to have been given the opportunity to undertake the challenging endeavor of writing a doctoral thesis. It has not been a lonesome journey. There are many people I wish to thank for their engagement in this project.

First of all, I want to thank the social workers who let me learn from their daily practices and who shared their thoughts concerning the situations that we encountered together. Then, I wish to thank my supervisors for their constant support. Per-Erik Ellström for enlightening me with his wisdom and tremendous knowledge in the field of learning. Per Nilsen for his meticulous efficiency in reading all the texts that I have produced and in his challenging inquiries.

Stephen Billett, thank you for your warm hospitality and encouraging discussions during my visit in Brisbane and at Griffith University. Cheers also to Darryl, Sarojni and Raymond for taking such good care of me. Madeleine Abrandt Dahlgren, your input into the second study was invaluable - suddenly the findings somehow just appeared! Verner Denvall and Anna-Lena Lindquist, I am grateful for your contributions at the thesis seminaries. Your interest in my research led to valuable discussions that helped me furthering my work.

It has been said that good managers surround themselves with the necessary expertise; I think that it works the other way around as well. I wish to address two managers: Björn Svensson, I have often wondered if this journey would have been undertaken without your encouragements during my working experiences at Jönköping Municipality. Gisela Eckert, thank you for helping me manage the balance between studies and lecturing. Also, I send grateful greetings to all colleagues at the division of Education and Sociology at Linköping University and Helix Vinn Excellence Centre as well as former colleagues in Jönköping. 
Sofia Enell and Jessica Sjögren, your insights into social work practice have been greatly valued. I certainly hope that our engaging discussions will continue. Sofia Kjellström, I look forward to many more «walks and talks.» It is a great way to reflect on various matters! Camilla Lindqvist, life sure is a rollercoaster. Thank you for your encouragements in the ups and downs.

Last but not least, I send my love to my family. My beautiful mother Anita, loving and caring sister Moni and big brother Christer, always ready to lend a helping hand - thanks for being the persons you are. Gabi and Jesper thank you for letting me be part of your lives. You guys make me so proud!

Johan, «the times they are a-changin»» Together in life we are unbeatable. I can't wait to see what the future has in store for us!

Stora Roten, April 2015

Gunilla Avby 


\section{References}

Aagaard Nielsen, K. \& Svensson, L. (Eds.) (2006) Action research and interactive research-beyond practice and theory. Maastricht: Shaker.

Abbott, A. D. (1988) The system of professions. Chicago: University of Chicago Press. Agar, M. H. (1996) The professional stranger (2nd ed.). San Diego: Academic Press. Alvesson, M. \& Spencer, A. (20I2) A stupidity-based theory of organizations. Journal of Management Studies, 49(7), II94-I220.

Amara, N., Ouimet, M. \& Landry, R. (2004) New evidence on instrumental, conceptual, and symbolic utilization of university research in government agencies. Science Communication, 26(I) 75-106.

Aristotle. (Ed.) (1967) Den nikomachiska etiken. [Nicomachean ethics] (M. Ringbom, Trans. \& Ed.) Göteborg: Diadalos.

Backer, T. E. (199I) Knowledge utilization: The third wave. Science Communication, I2(3), 225-240.

Baldwin, M. (2004) Critical reflection: Opportunities and threats to professional learning and service development in social work organizations. In N. Gould \& M. Baldwin (Eds.) Social work, critical reflection and the learning organization. Aldershot: Ashgate.

Barkham, M. \& Mellor-Clark, J. (2003) Briding evidence-based practice and practice-based evidence: Developing a rigorous and relevant knowledge for psychological therapies. Clinical Psychology and Psychotherapy, Iо, 319-327.

Barratt, M. (2003) Organizational support for evidence-based practice within child and family social work: a collaborative study. Child E Family Social Work, 8(2), I43-I50.

Bergmark, A., Bergmark, Å. \& Lundström, T. (20II) Evidensbaserat socialt arbete. Teori, kritik, praktik [Evidence-based social work. Theory, critism, practice.] Stockholm: Natur \& Kultur. 
Bergmark, A., Bergmark, A. \& Lundstrom, T. (2012) The mismatch between the map and the terrain-evidence-based social work in Sweden. European journal of social work, 15(4), 598-609.

Bergmark, Å. \& Lundström, T. (2002) Education, practice and research. Knowledge and attitudes to knowledge of Swedish social workers. Social Work Education, 2I(3), 359-373.

Bergmark, A. \& Lundström, T. (2005) En sak i taget?: Om specialisering inom socialtjänstens individ- och familjeomsorg. [One thing at a time?: About specialization in social welfare services] Socialvetenskaplig tidskrift (social science journal) I2 (2-3), I25-I48.

Bergmark, A. \& Lundström, T. (2007) Att studera rörliga mål - om villkoren för evidens och kunskapsproduktion i socialt arbete. [To study mobile (movable) targets: on the condisions of evidence and knowledge production in social work] Socialvetenskaplig tidskrift (social science journal) I4(I), 77-82.

Bergmark, A. \& Lundström, T. (2008) Evidensfrågan och socialtjänsten: om socialarbetares inställning till en vetenskapligt grundad praktik. [The evidence issue and the social services: on social workers' attitudes (point of view) to a practice based on science] Socionomens forskningssupplement (2I), 5-I4.

Biesta, G. (2007) Why "What works" wont't work: Evidence-based practice and the democratic deficit in educational research. Educational Theory, 57(I), I-22.

Billett, S. (200I) Learning through work: Workplace affordances and individual engagement. Journal of workplace learning, I3(5), 209-2I4.

Billett, S. (2002) Workplace pedagogic practices: Co-participation and learning. British Journal of Educational Studies, 50(4), 457-48I.

Billett, S. (2004) Learning through work: Workplace participatory practices. In H. Rainbird, A. Fuller \& A. Munro (Eds.) Workplace learning in context (pp. Io9-I25). London: Routledge.

Blomfield, R. \& Hardy, S. (200o) Evidence-based Nursing Practice. In L. Trinder \& S. Reynolds (Eds.) Evidence-based practice: A critical appraisal. Oxford: Blackwell Science.

Bohlin, I. \& Sager, M. (20II) Evidensens många ansikten: evidensbaserad praktik $i$ praktiken. [The many faces of evidence-based practice in practice] Lund: Arkiv. Brante, T. (2013) The professional landscape: The historical development of professions in Sweden. Professions Ẽ professionalism, $3(2)$. 
Brante, T., Johnsson, E., Olofsson, G. \& Svensson, L. (2014) Professionerna i kunskapssambället. En jämförande studie av svenska professioner 1996 och 2010. [Professions in knowledge society. A comparative study of Swedish professions 1996 and 2010] Retrieved: 2015-03-06, http://www.profland.net.

Brehmer, B. (1980) In one word: Not from experience. Acta Psychologica, 4, 223-24I. Broadhurst, K., Hall, C., Wastell, D., White, S. \& Pithouse, A. (2oro) Risk, instrumentalism and the humane project in social work: Identifying the informal logics of risk management in children's statutory services. British Journal of Social Work, 40(4), 1046-Io64.

Börjeson, M. \& Johansson, K. (20I4) In search for a model for knowledge production and practice research in Swedish social work. Nordic Social Work Research, 4(I), 70-85.

Cochrane, A. (1972) Effectiveness and efficiency: random reflections on health services. London: Nuffield Provincial Hospitals Trust.

Dahlgren, M.A. (1998) Learning physiotherapy: Students' ways of experienceing the patient encounter. Physiotherapy Research International, 3(4), 257-273.

Dahlgren, L-O. \& Fallsberg, M. (199I) Phenomenography as a qualitative approach in social pharmacy 'esearch'. Journal of Social and Administrative Pharmacy, 8, 150-156.

Davies, P. (1999) What is evidence-based education? British journal of educational studies, 47(2), 108-I21.

Dewey, J. (1917) The need for a recovery of philosophy. In H. H. a. company (Ed.) Creative intelligence - essays in the pragmatic attitude. Rahway, N.J.: The Quinne \& Boden Co. Press.

Dewey, J. (I9Iо) How we think; A restatement of the relation of reflective thinking in the educative process. Boston: D.C. Health \& Co.

Drury-Hudson, J. (1999) Decision making in child protection. The use of theoretical, empirical and procedural knowledge by novices and experts and inplication for fieldwork placement. British Journal of Social Work, 29(I), I47-I69.

Eason, P. \&Wilcockson, J. (1996) Intuition and rational decision-making in professional thinking: a false dichotomy? Journal of Advanced Nursing, 24, $667-673$.

Eikeland, O. (2006) Validity of action research and validity in action reserach. In L. Svensson \& K. Aagaard Nielsen (Eds.) Action research and interactive research: Beyond practice and theory. Maastricht: Shaker. 
Ellström, P-E. (200I) Integrating learning and work: Problems and prospects. $H u$ man Resource Development Quarterly, I2(4), 42I-435.

Ellström, P-E. (2006) The meaning and role of reflection in informal learning at work. In D. Boud, P. Cressey \& P. Docherty (Eds.) Productive reflection at work. Oxford: Routledge.

Ellström, P-E. (2009) The use and benefits of evaluations: a learning perspective. In L. Svensson, G. Brulin, S Jansson, \& K. Sjöberg (Eds.) Learning through ongoing evaluation. Lund: Studentlitteratur.

Ellström, P-E. (20II) Informal learning at work: conditions, processes and logics. In M. Malloch, L. Cairns, K. Evans \& B. N. O'Connor (Eds.) The Sage handbook of workplace learning. London: SAGE.

Eraut, M. (2000) Non-formal learning and tacit knowledge in professional work. British Journal of Educational Psychology, 70(1), 113-136.

Eraut, M. (2004a) Practice-based evidence. In G. Thomas \& R. Pring (Eds.), Evidence-based practice in education (pp. 9I-IoI). New York: Open University Press.

Eraut, M. (2004b) Informal learning in the workplace. Studies in Continuing Education, $26(2), 247^{-273}$.

Eraut, M. (2007) Learning from other people in the workplace. Oxford review of education, 33(4), 403-422.

Ericsson, K. A., Krampe, R. T. \& Tesch-Römer, C. (1993) The role of deliberate practice in the acquisition of expert performance. Psychological Review, Ioo(3), 363-406.

Estabrooks, C. A., Rutakumwa, W., O’Leary, K. A., Profetto-McGrath, J., Milner, M., Levers, M. J. \& Scott-Findlay, S. (2005) Sources of Practice Knowledge Among Nurses. Qualitative Health Research, I5(4), 460-476.

Evans, K. (in print) Developing knowledgeable practice at work. In M. Elg, P-E. Ellström, M. Klofsten \& M. Tillmar. Sustainable development in organizations. Cheltenham: Edward Elgar

Evetts, J. (20I0) Reconnecting professional ocuupations with professional organizations: risks and opportunities. In L. G. Svensson \& J. Evetts (Eds.), Sociology of professions. Continental and Anglo-Saxon traditions (pp. I23-I44). Borås: Diadalos. 
Evetts, J. (20I4) The concept of professionalism: Professional work, professional practice and learning. In H. Gruber, C. Harteis \& S. Billett (Eds.) International handbook of research in professional and practice-based learning. Dordrecht: Springer.

Ferdinand, J., Pearson, G., Rowe, M. \& Worthington, F. (2007) A different kind of ethics. Ethnography, 8(4), 519-543.

Ferguson, H. (20I4) What social workers do in performing child protection work: evidence from research into face-to-face practice. Child E Family Social Work, $\mathrm{n} / \mathrm{a}-\mathrm{n} / \mathrm{a}$.

Flyvbjerg, B. (2006) Five misunderstandings about case-study research. Qualitative Inquiry, $12(2), 219-245$.

Foss Hansen, H. (2014) Organisation of evidence-based knowledge production: Evidence hierarchies and evidence typologies. Scandinavian Journal of Public Health, 42 (I3), $\mathrm{II}^{-} \mathrm{I} 7$.

Fuller, A., Munro, A. \& Rainbird, H. (2004) Introduction and overview. In H. Rainbird, A. Fuller \& A. Munro (Eds.) Workplace learning in context (pp. I-I8). London: Routledge.

Gambrill, E. (1999) Evidence-based practice: an alternative to authority-based practice. Families in society: The Journal of Contemporary Human Services, 80, $34 \mathrm{I}^{-} 35 \mathrm{O}$.

Gambrill, E. (2007) Views of evidence-based practice: Social workers' code of ethics and addreditation standards as guides for choice. Journal of Social Work Education, 43(3), 447-462.

Gambrill, E. (20I2) Behavioural perspectives. In M. Gray, J. Midgley \& S. A. Webb (Eds.) The Sage handbook of social work. London: SAGE.

Gibbs, L. \& Gambrill, E. (2002) Evidence-based practice: Counterarguments to objections. Research on Social Work Practice, $12(3), 45^{2-476 . ~}$

Giddens, A. (1984) The constitution of society. Berkeley: University of California Press.

Gillingham, P. \& Humphreys, C. (2010) Child protection practitioners and decision-making tools: Observations and reflections from the front line. British Journal of Social Work, 40, 2598-2616.

Gray, M., Joy, E., Plath, D \& Webb, S. (2014) Opinions about evidence: A study of social workers' attitudes towards evidence-based practice. Journal of Social Work, I4(I), 23-40. 
Gray, M., Plath, D. \& Webb, S. A. (2009) Evidence-based social work. A critical stance. London: Routledge.

Gustavsson, B. (2004) Revisiting the philosophical roots of practical knowledge, In J. Higgs, B. Richardson \& M. Abrandt Dahlgren (Eds.) Developing practice knowledge for health professionals. London: Butterworth-Heinemann.

Hager, P. (2004) The conceptualization and measurement of learning. In H.

Rainbird, A. Fuller \& A. Munro (Eds.) Workplace learning in context (pp. 242-258). London: Routledge.

Hall, C. \& White, S. (2005) Looking inside professional practice: Discourse, narrative and ethnographic approaches to social work and counselling. Qualitative Social Work, 4(4), 379-390.

Hammarsley, M. (2009) What is evidence for evidence-based practice? In H-U. Otto, A. Polutta \& H. Ziegler (Eds.) Evidence-based practice- modernising the knowlege base of social work? Opladen \& Farmington Hills: Barbara Budrich.

Hanberger, A., Blom, B., Mårald, G. \& Perlinski, M. (20II) Regionala strukturer till stöd för kunskapsutveckling inom äldreområdet - förstudie inför utvärderingen av ett treärigt pilotprojekt. [Regional structures as support for developing. knowledge in elderly care - a pre-study] Umeå: Umeå Centre for Evaluation Research.

Hasselbladh, H., Bejerot, E. \& Gustafsson, R.Å. (2008) Bortom new public management: institutionell transformation $i$ svensk sjukvaird. [Beyond new public management: institutionell transformations in Swedish health care] Lund: Academia adacta.

Hasu, M. (2005) In search of sensitive ethnography of change: Tracing the invisible handsoffs from technology developers to users. Mind, Culture, and Activity, I2(2), 90-II2.

Haynes, B., Devereaux, P. \& Gordon, G. (2002) Physicians' and patients' choices in evidence based practice: Evidence does not make decisions, people do. BMJ: British Medical Journal, 324(7350), 1350.

Healy, K. (2009) Case of mistaken identity: The social welfare professions and new public management. Journal of Sociology, 45(40I).

Humphries, B. (2003) What else counts as evidence in evidence-based social work? Social Work Education, 22(I), 8I-9I.

Jensen, K., Lahn, L.C. \& Nerland, M. (Eds.) (20I2) Professional learning in the knowledge society. Rotterdam: Sense. 
Jerdeby, U. (Ed.) (2008) Evidensbaserad praktik i socialt arbete. [Evidence-based practice in social work] Stockholm Gothia/IMS.

Kahenman, D. (20II) Thinking fast and slow. London: Penguinn Books.

Klein, G. (I999) Sources of power. How people make decisions. Cambridge: MIT.

Knorr-Cetina, K.D. (198I) Time and context in practical action. Knowledge: Creation, Diffusion, Utilization, 3(2), I43-164.

Kvernbekk, T. (1999) Knowledge that works in practice. Scandinavian Journal of Educational Research, 43(2), III-I30.

Kvernbekk, T. (20II) The concept of evidence in evidence-based practice. Educational Theory, 6I(5), 515-532.

Larsen, J. K. (1980) Review Essay: Knowledge Utilization: What Is It? Science Communication, $I(3)$, 42I-442.

Lindblom, C.E. \& Cohen, D.K. (1979) Usable knowledge. social science and social problem solving. Newhaven, CT: Yale University Press.

Lindquist, A-L. (2012) Från krisande organisationer till "krisorganisationer" - Kvalité $i$ socialt barnavårdsarbete genom ökad personalstabilitet. [From troubled organizations to "organizations in crisis" - Quality in child welfare services through incresed personnel stability] Stockholm: Stiftelsen allmänna barnhuset.

Lipsky, M. (1980) Street-Level Bureaucracy (rev. ed.). New York: Russel Sage Foundation.

Marsh, P. \& Fisher, M. (2008) The development of problem-solving knowledge for social care practice. British Journal of Social Work, 38, 971-987.

Marsick, V.J. \& Watkins, K.E. (I990) Informal and incidental learning in the workplace. London: Routledge.

Marton, F. (198I) Phenomenography - describing conceptions of the world around us. Instructional Science, Io(2), $177^{-200 .}$

McCracken, S.G. \& Marsh, J.C. (2008) Practitioner expertise in evidence-based practice decision making. Research on Social Work Practice, I8(4), 30I-310.

Miles, M.B. \& Huberman, M. (1994) Qualitative data analysis: an expanded sourcebook. Thousand Oaks: SAGE.

Molander, A. \& Grimen, H. (2010) Understanding professional discretion. In L. Svensson \& J. Evertts (Eds.) Sociology of professions. Borås: Daidalos.

Morago, P. (2006) Evidence-based practice: from medicine to social work. European Journal of Social Work, 9(4), 461-477.

Mullen, E.J., Bledsoe, S.E. \& Bellamy, J.L. (2008) Implementing evidence-based social work practice. Research on Social Work Practice, $18(4), 325-338$. 
Munro, E. (1998). Improving Social Workers' Knowledge Base in Child Protection Work. British Journal of Social Work, 28(I), 89-I05.

Munro, E. (2010) Learning to reduce risk in child protection. British Journal of Social Work, 40(4), II35-II5I.

Munro, E. (20II) The Munro review of child protection: Final report - A childcentred system. London.

Nilsen, P., Roback, K., Brostrom, A. \& Ellstrom, P-E. (2012) Creatures of habit: accounting for the role of habit in implementation research on clinical behaviour change. Implementation Science, $7(\mathrm{I}), 53$.

Nonaka, I. \& Takeuchi, H. (1995) The knowledge-creating company. New York: Oxford University Press.

Nordlander, L. (2006) Mellan kunskap och handling - Om socialsekreterares kunskapsanvändning $i$ utredningsarbetet. [Between knowledge and action - about social workers' knowledge use in investigation work] (Doctoral) Umeå: Umeå University.

Nowotny, H., Scott, P. \& Gibbons, M. (2003) Introduction: 'Mode 2' revisited: The new production of knowledge. Minerva, $4{ }_{4}(3)$, I79-194.

Nutley, S., Walter, I. \& Davies, H.T.O. (2007) Using evidence: How research can inform public services. Bristol: The Policy Press.

Olsson, T.M. (2007) Reconstructing evidence-based practice: an investigation of three conceptualisations of EBP. The Policy Press, 3, 2, 27I-85.

Oscarsson, L. (2009) Evidensbaserad praktik inom socialtjänsten: en introduktion för praktiker, chefer, politiker och studenter. [Evidence-based practice in social care services: an introduction for practitioners, managers, polititians and students] Stockholm: sKL Kommentus.

Osmond, J. (200I) The practice of knowledge use: a study of the explicit and tacit understandings of practitioners. (Doctoral) Brisbaine: The University of Queensland.

Osmond, J. \& O'Connor I. (2006) Use of theory and research in social work practice: Implications for knowledge-based practice. Australian Social Work, 59(I), 5-19.

Otto, H.-U., Polutta, A. \& Ziegler, H. (2009) Reflexive professionalism as a second generation of evidence-based practice. Research on Social Work Practice, I9 (4), $472-478$.

Parton, N. (2008) Changes in the form of knowledge in social work. British Journal of Social Work, 38, 253-269. 
Patton, M.Q. (2002) Two decades of development in qualitative inquiry:

A personal, experiential perspective. Qualitative Social Work, 1(3), 26I-283.

Payne, M. (2007) Performing as a 'wise person' in social work practice. Practice:

Social Work in Action, I9(2), 85-96.

Polanyi, M. (1966) The tacit dimension. Chicago: University of Chicago Press.

Pawson, R., Boaz, A., Grayson, L., Long, A. \& Barnes, C. (2003) Types and quality of knowledge in social care. Knowledge review 3. London: sciE.

Rainbird, H., Fuller, A. \& Munro, A. (Eds.) (2004) Workplace learning in context. London: Routledge.

Rasmusson, B., Hyvönen, U., Nygren, L. \& Khoo, E. (2010) Child-centered social work practice - three unique meanings in the context of looking after children and the assessment framework in Australia, Canada and Sweden. Children and Youth Services Review, 32(3), 452-459.

Rich, R.F. (1991) Knowledge creation, diffusion, and utilization: Perspectives of the founding editor of knowledge. Science Communication, I2(3), 319-337.

Rosen, A. (1994) Knowledge use in direct practice. Social Service Review, 68(4), 56I-577.

Rosen, A. (2003) Evidence-based social work practice: Challenges and promise. Social Work Research, 27(4), 197-208.

Ryle, G. (1945) Knowing How and Knowing that: the presidential address. Proceedings of the Aristotelian Society, 46(n/a), 1-16.

Sackett, D.L., Rosenberg, W.M.C., Gray, J.A.M., Haynes, R. \& Richardson, W.S. (1996) Evidence based medicine: what it is and what it isn't. BMJ, British Medical Journal 3I2(7023), 71-72.

Sackett, D.L., Straus, S.E., Richardson, W.S., Rosenberg, W.M.C. \& Haynes, R.B. (2000) Evidence-based medicine - How to practice and teach $E B M$ (Second edition ed.). Edinburgh: Harcourt.

Sadler-Smith, E. (2014) Intuition in professional and practice-based learning. In H. Gruber, C. Harteis \& S. Billett (Eds.) International handbook of research in professional and practice-based learning. Dordrecht: Springer.

Sadler-Smith, E. \& Sheffy, E. (2004) The intuitive executive: Understanding and applying 'gut feel' in decision-making. Academy of Management Executive, I8(4), 76-9I. 
Satterfield, J. M., Bonnie Spring, R. C., Brownson, Edward J. Mullen, Robin P. Newhouse, Walker, B. B., \& Whitlock, E. P. (2009) Toward a Transdisciplinary Model of Evidence-Based Practice. Milbank Quarterly, 87(2), 368-390.

Schmidt, H.G. \& Boshuizen, H.P.A. (1993). On acquiring expertise in medicine. Educational Psychology Review, 5(3), 205-221.

Schön, D. A. (1983) The Reflective Practitioner - How professinals think in action. London: Basic Books Inc.

Seers, K., Cox, K., Crichton, N., Tudor Edwards, R., Eldh, AC., Estabrooks, C., Harvey, G., Hawkes, C., Kitson, A., Link, P., McCarthy, G., McCormack, B., Mockford, C., Rycroft-Malone, J. Titchen, A. \& Wallin, L. (2OI2) FIRE (Facilitating Implementation of Research Evidence): a study protocol. Implementation Science, 7(25).

Sellbjer, S. \& Jenner, H. (20I2) How to unite scientific reasoning and practical knowledge in teacher education: as illustrated by a postgraduate course, International Journal of Education, 4, 220-231.

Senge, P. (1990) The fifth discipline: The art and practice of the learning organization. New York: Doubleday.

Sheppard, M., Newstead, S., Di Caccavo, A., \& Ryan, K. (2000) Reflexivity and the development of process knowledge in social work: a classification and empirical study. British Journal of Social Work, 30(4), 465-488.

Sheppard, M., \& Ryan, K. (2003) Practitioners as Rule Using Analysts: A Further Development of Process Knowledge in Social Work. British Journal of Social Work, 33(2), I57-176.

Sherman, L. W. (1998) Evidence-Based Policing. I6.

SKL. (20I2) Sveriges kommuner och landsting [Swedish Association of Local Authoritiesand Regions]. www.skl.se.

Socialstyrelsen. (2006) Grundbok Barns Behov i [Centrum Children's Needs in Focus]. Retrieved: 2013-02-15, Stockholm.

Socialstyrelsen \& SKL. (20II) På väg mot en evidensbaserad praktik inom socialtjänsten. [On the road to evidence-based practice in social services] Retrieved: 20II-0509, Stockholm.

Socialstyrelsen. (2014) Öppna jämförelser. Social barn-och ungdomsvård. [Quality and efficiency. Child welfare services] Retrieved: 2015-04-04, Stockholm. 
Socialstyrelsen. (2015) Tillståndet och utvecklingen inom hälso- och sjukvård och socialtjänst. [The state and development in Swedish health care and social services] Retrieved: 2015-03-II, Stockholm.

SOU. (2008:68) Evidensbaserad praktik inom socialtjänsten - till nytta för brukaren: betänkande av utredningen för en kunskapsbaserad socialtjänst [Evidence-based practice within social care services - to the user's benefit] Stockholm: Fritzes.

Soydan, H. (2010) Evidence and policy: the case of social care services in Sweden. The Policy Press, 6(2), I79-I93.

SSR (I997) Yrkesetiska riktlinjer för socionomer.

Sundell, K., Brännström, L., Larsson, U. \& Marklund, K. (2008) På väg mot en evidensbaserad praktik. [On the road to evidence-based practice. 834 municipal social work managers on EBP and the use of EBPs in social services] Stockholm: IMs/Socialstyrelsen.

Svensson, L. (20I0) Professions, organizations, collegiality and accountability. In L. G. Svensson \& J. Evetts (Eds.), Sociology of professions. Continental and Anglo-Saxon traditions (pp. I45-I66). Borås: Diadalos.

Svensson, L. (20II) Inledning till studier av professioner och professionellt arbete. [Introduction to studies in professions and professional work] Socialvetenskaplig tidskrift, 4, 254-267.

Svensson, L. \& Evetts, J. (2010) Introduction. In L. Svensson \& J. Evetts (Eds.) Sociology of professions. Continental and Anglo-Saxon traditions (pp. 8-29). Borås: Diadalos.

Tengvald, K. (2008) Den evidensbaserade praktiken i sitt sammanhang. [The context of evidence-based practice] In U. Jergeby (Ed.), Evidensbaserad praktik $i$ socialt arbete [Evidence-based practice in social work] Stockholm: Gothia/ IMS.

Thyer, B.A. (20I2) Evidence-based practice and social work. In M. Gray, J. Midgley \& S. A. Webb (Eds.) The Sage handbook of social work. Londeon: SAGE. Thyer, B.A. (2006) What is evidence-based practice? In A.R. Roberts \& K.R. Yeager (Eds.) Foundations of evidence-based social work practice. Oxford: Oxford University Press.

Timmermans, S. \& Berg, M. (2003) The Gold Standard. The challenge of evidencebased medicine and standardization in health care. Philadelphia: Temple University Press.

Tobin, G. \& Begley, C. Methodological rigour within a qualitative framework. Journal of Advanced Nursing, 48(4), 388-396. 
Trevithick, P. (2008) Revisiting the knowledge base of social work: A framework for practice. British Journal of Social Work, 38(6), I2I2-I237.

Trinder, L. (2000a) A critical appraisal of Evidence-Based Practice. In L. Trinder \& S. Reynolds (Eds.) Evidence-Based Practice: A Critical Appraisal (pp. 2I2-24I). Oxford: Blackwell Science.

Trinder, L. (200ob) Introduction: the context of evidence-based practice. In L. Trinder \& S. Reynolds (Eds.) Evidence-based practice. A critical appraisal. Oxford: Blackwell Science.

Tynjälä, P. (2008) Perspectives into learning at the workplace. Educational Research Review, 3(2), I30-I54.

Uggerhøj, L. (20II) Theorizing practice research in social work. Social Work and Social Sciences Review, I5(I), 49-73.

Vagli, Å. (2009) Behind closed doors. Exploring the institutional logic of child protection work. (Doctorial) Bergen: University of Bergen.

Van de Luitgaarden, G. (2009) Evidence-Based Practice in Social Work: Lessons from Judgment and Decision-Making Theory. British Journal of Social Work, 39, 234-260.

Van de Luitgaarden, G. (20II) Contextualizing judgements and decisions in child protection practice at the point of first referral. Journal of Social Interventions: Theory and Practice, 20(3), 24-40.

Walton, D.N. (I990) What is reasoning? What is an argument? Journal of Philosophy, 87(8), 399-4I9.

Wastell, D. \& White S. (2009) Unsettling evidence and lively language: reflexive practitioner as trickster. In. H-U. Otto, A. Polutta \& H. Ziegler (Eds.) Evidence-based practice - modernising the knowlege base of social work? Opladen \& Farmington Hills: Barbara Budrich.

Webb, S. (200I) Some considerations on the validity of evidence-based practice in social work. British Journal of Social Work, 3I(I), 57-79.

Weick, K.E. \& Westley, F. (r996) Organizational learning affirming an oxymoron. In S.R. Clegg, C. Hardy \& W.R. Nord (Eds.) Handbook of organization studies. London SAGE.

Weiss, C. (I979) The many meanings of research utilization. Public Administration Review, (September/October), 426-43I.

Weiss, C. \& Bucuvalas, M.J. (I980) Truth tests and utility tests: decision-makers' frames of reference for social science research. American Sociological Review, 45(April), 302-3I3. 
White, S. (1997) Beyond retroduction? - Hermeneutics, reflexivity and social work practice. British Journal of Social Work, 27(5), 739-753.

White, S. (2009) Fabled uncertainty in social work. A coda to Spafford et al. Journal of Social Work, 9(2), 222-235.

WorkingGroup, E.-B.M. (1992) A new approach to teaching the practice of medicine. Journal of the American Medical Association, 268, 2420-2425.

Zollo, M. \& Winter, S.G. (2002) Deliberate Learning and the Evolution of Dynamic Capabilities. Organizational Science, 13(3), 339-35I.

Åkerlind, G. (2005) Phenomenographic methods: a case illustration. In J.A.B.P. Green (Ed.) Doing developmental phenomenography. Melbourne: RMIT University.

Östberg, F. (20I0) Bedömningar och beslut. Från anmälan till insats i den sociala barnavården. [Assessments and decisions. From report to intervention in child welfare services] (Doctoral) Stockholm: Stockholm University. 


\section{Articles}

The articles associated with this thesis have been removed for copyright reasons. For more details about these see:

http://urn.kb.se/resolve?urn=urn:nbn:se:liu:diva-117912 


\section{Linköping Studies in Behavioural Science}

166. SANDBERG, FREDRIK. Recognition of Prior Learning in Health Care. From a Caring Ideology and Power, to Communicative Action and Recognition. 2012. ISBN: 978-917519-814-9

167. FÄGERSTAM, EMILIA. Space and Place. Perspectives on Outdoor Teaching and Learning. 2012. ISBN: 978-91-7519-813-2

168. FALKENSTRÖM, FREDRIK. The Capacity for Self-Observation in Psychotherapy. 2012. ISBN: 978-91-7519-797-5

169. BENNICH, MARIA. Kompetens och kompetensutveckling i omsorgsarbete. Synen på kompetens och lärande i äldreomsorgen - i spänningsfältet mellan samhälleliga förutsättningar och organisatoriska villkor. 2012. ISBN: 978-91-7519-777-7

170. RUSANGANWA, JOSEPH. Enhancing Physics Learning through Instruction, Technical Vocabulary and ICT. A Case of Higher Education in Rwanda. 2012. ISBN: 978-91-7519$739-5$

171. MBABAZI, PENELOPE. Quality in Learning in Rwandan Higher Education: Different Stakeholders' Perceptions of Students' Learning and Employability. 2013. ISBN: 978-917519-682-4

172. BYSTRÖM, ERICA. Ett lärorikt arbete? Möjligheter och hinder för under-sköterskor att lära och utvecklas i sjukvårdsarbetet. 2013. ISBN: 978-91-7519-679-4

173. KAGWESAGE, ANNE MARIE. Coping with Learning through a Foreign Language in Higher Education in Rwanda. 2013. ISBN: 978-91-7519-640-4

174. MUTWARASIBO, FAUSTIN. Understanding Group-based Learning in an Academic Context: Rwandan Students' Reflections on Collaborative Writing and Peer Assessment. 2013. ISBN: 978-91-7519-633-6

175. MÅRDH, SELINA. Cognitive erosion and its implications in Alzheimer's disease. 2013. ISBN: 978-91-7519-612-1

176. HARLIN, EVA-MARIE. Lärares reflektion och professionella utveckling - Med video som verktyg. 2013. ISBN: 978-91-7519-611-4 
177. ÖSTERGREN, RICKARD. Mathematical Learning Disability. Cognitive Conditions, Development and Predictions. 2013. ISBN: 978-91-7519-565-0

178. ENGVALL, MARGARETA. Handlingar i matematikklassrumet. En studie av undervisningsverksamheter på lågstadiet då räknemetoder för addition och subtraktion är i fokus. 2013. ISBN: 978-91-7519-493-6

179. JOHANSSON, ROBERT. Treating depression and its comorbidity. From individualized Internet-delivered cognitive behavior therapy to affect-focused psychodynamic psychotherapy. 2013. ISBN: 978-91-7519-467-7

180. BERGMAN NORDGREN, LISE. Individually tailored internet-based cognitive behavioural therapy for anxiety disorders. 2013. ISBN: 978-91-7519-459-2

181. FREJD, PETER. Modes of Mathematical Modelling. An Analysis of how modelling is used and interpreted in and out of school settings. 2014. ISBN: 978-91-7519-414-1

182. AMAN, ROBERT. Impossible Interculturality? Education and the Colonial Difference in a Multicultural World. 2014. ISBN: 978-91-7519-348-9

183. NYLANDER, ERIK. Skolning i jazz. Värde, selektion och studiekarriär vid folkhögskolornas musiklinjer. 2014. ISBN: 978-91-7519-347-2

184. GRADIN FRANZÈN, ANNA. Disciplining freedom: Treatment dilemmas and subjectivity at a detention home for young men. 2014. ISBN: 978-91-7519-344-1

185. ENGSTRÖM, ANNIKA. Lärande samspel för effektivitet. En studie av arbetsgrupper i ett mindre industriföretag. 2014. ISBN:978-91-7519-345-8

186. ELWÉR, ÅSA. Early Predictors of Reading Comprehension Difficulties. 2014. ISBN: 97891-7519-281-9

187. LARSON, NICLAS. Matematikämnet och stadiebytet mellan grundskolan och gymnasieskolan. En enkät- och klassrumsstudie. 2014. ISBN: 978-91-7519-196-6

188. LY, HOA. Use of a Smartphone Application in the Treatment of Depression - The New Wave of Digital Tools for Psychological Treatment. 2015. ISBN: 978-91-7519-136-2

189. HANSSON, PER-OLOF. New ways of learning. Participatory action research and Kenyan runners' appropriation of smartphones to improve their daily lives and participation in $\mathrm{m}$ learning. 2015. ISBN: 978-91-7519-124-9

190. BOLLDÈN, KARIN. Online teaching practices. Sociomaterial matters in higher education settings. 2015. ISBN: 978-91-7519-123-2

191. MALMQUIST, ANNA. Pride and Prejudice. Lesbian families in contemporary Sweden. 2015. ISBN: 978-91-7519-087-7 
